Illinois State University

ISU ReD: Research and eData

Theses and Dissertations

$5-21-2019$

\title{
Characterization Of Pth Type-2 Receptor (pth2rb) And Its Endogenous Ligand Pth2 In Zebrafish Development
}

Nicholas Seitz

Illinois State University, nonotnick@gmail.com

Follow this and additional works at: https://ir.library.illinoisstate.edu/etd

Part of the Cell Biology Commons, and the Developmental Biology Commons

\section{Recommended Citation}

Seitz, Nicholas, "Characterization Of Pth Type-2 Receptor (pth2rb) And Its Endogenous Ligand Pth2 In Zebrafish Development" (2019). Theses and Dissertations. 1131.

https://ir.library.illinoisstate.edu/etd/1131

This Dissertation is brought to you for free and open access by ISU ReD: Research and eData. It has been accepted for inclusion in Theses and Dissertations by an authorized administrator of ISU ReD: Research and eData. For more information, please contact ISUReD@ilstu.edu. 
CHARACTERIZATION OF PTH TYPE-2 RECEPTOR (PTH2RB) AND ITS ENDOGENOUS

LIGAND PTH2 IN ZEBRAFISH DEVELOPMENT

\section{NICHOLAS SEITZ}

72 Pages

Members of the parathyroid hormone family of ligands, PTH (parathyroid hormone), PTH2, and PTHLH (parathyroid hormone-like hormone). These hormones interact with the class B GCPRs parathyroid hormone receptors PTH1R, PTH2R, and PTH1Rb/3R to regulate a variety of biological processes. In mammals, PTH and PTHLH activate PTH1R and PTH1Rb/3R to mediate serum calcium homeostasis, chondrogenesis, and bone maintenance. PTH2R activation by PTH2 has been studied primarily in regard to its neuroendocrine roles but is also found in the skin where it contributes to wound healing and keratinocyte differentiation. Still, little is known about the impacts of PTH2R signaling relative to PTH1R and PTH1Rb/3R. Here, we identify and characterize a paralog of the zebrafish pth2r gene we call pth2rb. Expression studies reveal that pth2rb is detectable in the developing zebrafish forebrain-midbrain in close proximity to PTH2. Functional investigation of Pth2rb stimulation by PTH2 shows a greater maximum response in intracellular cAMP compared to that of zebrafish Pth2ra. Together these studies provide the initial groundwork for further evaluations of the PTH2/PTH2R signaling interactions that may be applicable across species.

KEYWORDS: Development, parathyroid hormone, endocrine, neuroendocrine, G-protein coupled receptor 
CHARACTERIZATION OF PTH TYPE-2 RECEPTOR (PTH2RB) AND ITS ENDOGENOUS

LIGAND PTH2 IN ZEBRAFISH DEVELOPMENT

NICHOLAS SEITZ

A Dissertation Submitted in Partial

Fulfillment of the Requirements

for the Degree of

DOCTOR OF PHILOSOPHY

School of Biological Sciences

ILLINOIS STATE UNIVERSITY

2019 
(C) 2019 Nicholas Seitz 


\title{
CHARACTERIZATION OF PTH TYPE-2 RECEPTOR (PTH2RB) AND ITS ENDOGENOUS \\ LIGAND PTH2 IN ZEBRAFISH DEVELOPMENT
}

\author{
NICHOLAS SEITZ
}

COMMITTEE MEMBERS:

Kevin Edwards, Chair

Craig Gatto

Alysia Mortimer

Tom Hammond

Laura Vogel 


\section{ACKNOWLEDGMENTS}

Dedicated to the memory of Dr. David Rubin, my friend and mentor. I'd like to thank all my committee members for keeping me on track and always offering me advice when things were difficult. Special thanks to Dr. Kevin Edwards for allowing me to finish my degree through working with him on projects in the D. melanogaster model system. Thanks to all members of the Rubin and Edwards labs that I've had the privilege to work with during my time at Illinois State University. I'd especially like to thank Dr. Scott Halkyard, Jay Berkes, Dr. Joe Powers, and Jennifer Achs for their enormous contributions towards much of the PTH2Rb work. I'd like to thank my collaborators, Dr. John Postlethwait, and Dr. Yi-Lin Yan at University of Oregon and Dr. Thomas Gardella at Massachusetts General Hospital for all their help and expertise. Finally, I'd like to thank the School of Biological Sciences at Illinois State, Dr. Craig Gatto, and Dr. Steve Juliano for their guidance and support. 


\section{CONTENTS}

Page

ACKNOWLEDGMENTS

TABLES

FIGURES

CHAPTER I: PARATHYROID HORMONE TYPE-2 RECEPTOR B 1

Introduction 1

$\begin{array}{ll}\mathrm{PTH} & 2\end{array}$

$\begin{array}{ll}\text { PTHLH } & 4\end{array}$

PTH1R and PTH1Rb/3R 4

$\mathrm{PTH} 2 \quad 5$

$\begin{array}{ll}\text { PTH2R } & 6\end{array}$

$\begin{array}{ll}\text { Results } & 6\end{array}$

$\begin{array}{ll}\text { Synteny and phylogenetic analysis of pth2rb } & 6\end{array}$

Evolutionary structural analysis indicates ligand binding site remodeling $\quad 8$

Developmental expression pattern has diverged in the pth2rb paralogs 9

$\begin{array}{ll}\text { Pth2rb is a functional PTH2 receptor } & 10\end{array}$

$\begin{array}{ll}\text { Discussion } & 11\end{array}$

$\begin{array}{ll}\text { CHAPTER II: PEZ } & 28\end{array}$

$\begin{array}{ll}\text { Introduction } & 28\end{array}$

$\begin{array}{ll}\text { Results } & 31\end{array}$

$\begin{array}{ll}\text { Discussion } & 32\end{array}$ 
Introduction

Results

Discussion

REFERENCES

Pth2rb

Pez

GAL4 Toxicity

APPENDIX A: METHODS AND MATERIALS

APPENDIX B: SUPPLEMENTARY TABLES \& FIGURES 


\section{TABLES}

Table

Page

1.1. Nomenclature of PTH ligands and receptors

1.2. Measurements of GloSensor cAMP-dependent luminescence in transfected HEK-293 cells

1.3. P-values of zPth2rb vs. zPth2ra

2.1. Complete, nonredundant set of standard tyrosine-specific kinases in D. melanogaster

2.2. Tyrosine kinase RNAi lines used for UAS-Pez cross 


\section{FIGURES}

Figure

Page

1.1. Alignment of Danio and Human PTHR family members

1.2. Syntenic analysis of pth2rb orthologs and paralogs

1.3. Phylogenetic analysis of PTH receptor family

1.4. Crystal structure of PTH1R (PDB 6FJ3; Ehrenmann et al. 2018)

1.5. Close-up of PTH1R crystal structure (PDB 6FJ3; Ehrenmann et al. 2018)

1.6. In situ hybridization detection of pth2rb

1.7. Coronal cryosections in situ hybridizations to detect pth ligands and receptors

1.8. Whole mount in situ hybridization detection of pth2ra

1.9. Evaluation of cAMP activity by PTH ligands

2.1. Accumulation of Pez and pTyr proteins in the presence of kinase RNAi

2.2. Accumulation of Pez and pTyr proteins in the presence of Src42A RNAi

3.1. Wing phenotypes of GAL80ts crossed to $s d^{R 94 B 03}-G A L 4$

3.2. Wing phenotypes of UAS-p35 crossed to $s d^{R 94 B 03}-G A L 4$ 


\section{CHAPTER I: PARATHYROID HORMONE TYPE-2 RECEPTOR B}

\section{Introduction}

The Parathyroid hormone (PTH) system has evolved in chordates to perform diverse functions including calcium homeostasis and signaling, embryonic development, reproductive physiology/behavior, nociception, and fear/anxiety responses (Cheloha et al. 2016; SuarezBregua et al. 2017). PTH, Parathyroid hormone 2 (PTH2, alias TIP39) and Parathyroid-like hormone (PTHLH, alias parathyroid hormone-related protein) interact with a family of class B G-protein coupled receptors (GPCRs) comprised of PTH1R, PTH1Rb/3R, and PTH2R (Rubin \& Jüppner, 1999; see Table 1 for nomenclature key). PTH and PTHLH are able to bind and activate PTH1R to produce a cAMP response via activation of $\mathrm{G} \alpha_{\mathrm{S}}$ (Gardella \& Jüppner, 2001; Cheloha et al. 2016; Ehrenmann et al. 2018). PTH2R is able to bind PTH and PTH2 but displays different activation profiles between these two ligands (Usdin et al. 1999; Bisello et al. 2004). PTH2 stimulation triggers recruitment of $\mathrm{PKC} \beta$ and $\beta$-arrestin, receptor desensitization, and receptor internalization whereas PTH does not (Bisello et al 2004). The elevated potency displayed by PTH2 stimulation supports its role as PTH2R's primary ligand. PTH and PTHLH activity are involved in regulating renal fibrosis, chondrogensis, nociception, bone development and maintenance in mammals and likely fish (Guo et al. 2017; Yan et al. 2012; Miao et al. 2012; Miao et al. 2008; Guerreiro et al. 2007; Shepherd et al. 2018; Gardinier et al. 2019; Hong et al. 2019; He et al. 2018; Nishimori et al. 2019; White et al. 2019). PTH is an important component in osteoporosis and kidney disease therapy (Swarthout et al. 2002; Chen et al. 2018; Mantovani and Elli, 2019). Deregulation of PTHLH contributes to humoral hypercalcemia of malignancy, intrahepatic cholangiocarcinoma, breast cancer, and disrupted T-cell development (Guerreiro et al. 2007; Mangin et al. 1988; Tran et al. 2018; Jia et al. 2017; Tang et al. 2017; Pinheiro et al. 
2012). Neuroendocrine studies suggest PTH2R activity contributes to thermal sensitivity, spine disease, nociception, the fear/anxiety response, and inflammation (Dimitrov et al. 2011; Åkesson et al. 2015; Gellén et al. 2017; Dimitrov et al. 2013; Dobolyi et al. 2012; Tsuda et al. 2015). PTH2 has also been shown to influence bone development, keratinocyte differentiation and wound repair in the skin (Panda et al. 2012; Wilgus, 2017; Sato et al. 2016; Sato et al. 2017).

We have previously observed pth2 and $p t h 2 r$ by in situ hybridization in early zebrafish development (Papasani et al. 2004; Bhattacharya et al. 2011). Pth2 mRNAs can be detected at the beginning of the blastula stages ( $4 \mathrm{hpf}$ ), the brain during segmentation ( $22 \mathrm{hpf})$, and paired forebrain-midbrain domains by the hatching period (48-72 hpf). Detectable levels of $p$ th $2 r$ can been seen very early during cleavage (1.75 hpf), throughout the CNS at 12 to $22 \mathrm{hpf}$, and becomes restricted to the midbrain-forebrain region and otic vesicles by $72 \mathrm{hpf}$. Here we analyze the fourth zebrafish PTH receptor homolog which we now refer to as $p t h 2 r b$ to distinguish it from the previously established zebrafish $p t h 2 r$ gene we will now call pth2ra (Papasani et al. 2004; Bhattacharya et al. 2011; Table 1). We report pth2rb isolation, syntenic and phylogenetic analysis, mRNA expression, and functional evaluation. We use the new pth2rb sequence and the recent crystal structure of PTH1R (Ehrenmann et al. 2018) to identify conserved specializations in the PTH2R family. Our aim is to provide initial characterization of an additional PTH2sensitive receptor in zebrafish which will further the understanding of PTH2/PTH2R signaling in vertebrates.

\section{PTH}

Secretion and synthesis of PTH is coordinated by primarily by the parathyroid gland in humans, while supplementary secretion by the thymus has been observed in other mammals. The physiological role of PTH in mammals is maintenance of extracellular calcium homeostasis 
and is utilized as a target in treatment of osteoporosis, chronic kidney disease, and maintenance of mesenchymal stem cell density (Risom et al. 2013; Frazier-Bowers et al. 2013; Ben-awadh et al. 2014; Chen et al. 2018; Tang et al. 2019). In zebrafish, which lack a parathyroid, PTH is synthesized at the brain, lateral line, and gills. The mature PTH hormone is an 84-residue polypeptide that is derived from pre-pro-PTH which includes a 25-residue extension at its $\mathrm{N}$ terminus. Structurally, the first 34 residues of PTH (PTH (1-34)) are critical for binding and activation of target receptors (Castro et al. 2002; Ben-awadh et al. 2014, Wang et al. 2014). PTH acts in the bone, skin, and kidney via its PTH type-1 receptor (PTH1R) interactions to regulate serum calcium levels. When serum calcium levels are high, $\mathrm{Ca}^{2+}$ ions bind to calcium sensing receptors (CaSR) on the surface of the parathyroid to inhibit PTH secretion (Brown et al. 1993). At low calcium serum levels, PTH is secreted by the parathyroid to act directly at the bone and kidney, skin, and indirectly on the intestines. In bone, PTH binds to its target receptor, PTH1R, to initiate the activation of adenylate kinase leading to cAMP accumulation and subsequent phosphokinase A (PKA) pathway. In response to PKA pathway activity, cytokines are released by osteoblasts stimulating calcium, phosphate, and magnesium resorption from bone (Schluter, 1999; Guerreiro et al. 2007).

In the kidney, binding of PTH with its target receptors stimulates the phosphokinase C (PKC) pathway and activations of the $1 \alpha$ hydroxylase renal enzyme. Renal $1 \alpha$ hydroxylase then converts vitamin D to its active form to promote calcium uptake in the intestines (Garabedian et al. 1972; Fraser and Kodicek, 1973). More recently, examination of PTH activity in cutaneous tissue has shown that extracellular $\mathrm{Ca}^{2+}$ binds PTH1R and assists in sustaining the endosomal cAMP cascade (White et al. 2019). 


\section{PTHLH}

The PTH-like hormone (PTHLH) was first isolated from neck, head, and lung tumors of patients suffering from humoral hypercalcemia of malignancy (HHM), a condition arising from adult T-cell leukemia/lymphoma (ATL) (Jans et al. 2003; Guerreiro et al. 2007). PTHLH possess a highly similar N-terminal domain with the first 34 amino acids of PTH and is able to bind equivalently to PTH receptors, PTH1R and PTH1Rb/3R, as PTH. PTHLH is required for development of teeth, bone, pancreas, and is highly expressed in cartilage during chondrogenesis (Yan et al. 2012; Nishimori et al. 2019). Loss of PTHLH function is embryonic lethal and yields abnormal musculoskeletal phenotypes, shortened epiphyseal cartilages, and increased ossification during bone remodeling (Lam et al. 2000; Strewler and Nissenson, 2003).

\section{PTH1R and PTH1Rb/3R}

Parathyroid hormone receptors (PTHRs) are a group of class B G-couple protein receptors (GPCRs) that exhibit a seven-(pass)-transmembrane domain. GPCRs are most commonly associated with sensory functions and mediating signaling by ligand interaction. Class B GPCR binding and activation are functionally separate events which rely on interactions between different domains of the ligand and its target receptor. GPCR binding affinity is mediated by interaction between the C-terminal domain of the ligand with the extracellular Nterminal domain of the receptor. Activation is reliant on the interface of the N-terminal domain of the ligand with the receptor's transmembrane helices (Bergwitz et al. 1996). As the largest class of membrane receptors in the human genome, they are the target for many drugs intended for clinical use (Overington et al. 2006).

Several rounds of genome duplication events are responsible for the diversity of members in the parathyroid hormone gene family across extant vertebrates today. Zebrafish possess a 
number of duplicated paralogs that may be misidentified as 'novel' genes (Kang, 2004;

Postlethwait, 2007). Zebrafish possess two genes that encode PTHRs, $p t h 1 r$ and $p t h 1 r b / 3 r$, stimulated preferably by PTH or PTHLH. Mammals do not possess a PTHIRb/3R homolog and the function of zebrafish $p t h 1 r b / 3 r$ remains unclear. The structural similarity of PTH1R and PTH3R indicate they are likely co-orthologs derived from gene duplication. Despite being coorthologs the activation by PTH and PTHLH differs between PTH1R and PTH1Rb/3R. PTH1R is able to bind PTH, PTHLH, and PTH2 ligands, but only exhibits a cAMP response from PTH or PTHLH. PTH1Rb/3R binds PTH and PTHLH equivalently, but cAMP accumulation in response to PTH is significantly lower compared to PTHLH suggesting PTHLH as its primary ligand (Rubin and Jüppner, 1999).

\section{PTH2}

The peptide, parathyroid hormone 2 (PTH2) (also known as tuberoinfundibular peptide 39, TIP39) is a distant to relative to PTH/PTHLH and was first isolated from bovine brain. Mature PTH2 is a 39 amino acid peptide and share similar sequence identity to PTH (Papasani et al. 2004). Study of CNS expression in rat tissues has shown PTH2 to be synthesized in the posterior thalamic areas, medial paralemniscal nucleus, and dorsal/dorsolateral hypothalamus (John et al. 2002; Dobolyi et al. 2003), while overall distribution is observed throughout the CNS (Dobolyi et al. 2003). In zebrafish, PTH2 is detected at all stages, starting in early zygotes. Later, $P T H 2$ is restricted to the otic vesicles, heart, and the fore-midbrain boundary 48 hours post-fertilization (Papasani et al. 2004). PTH2 possesses activation and binding critical amino acid residues at positions 5 and 23, similar to PTH/PTHLH (Gardella et al. 1996). In COS-7 cells, human and mouse PTH2 has been shown to effectively bind and activate PTH2R to stimulate cAMP accumulation. Loss of PTH2 function by morpholino knockdown in zebrafish 
results in lethality at 3 days post-fertilization. These morphants display small otic vesicles and eyes, hindbrain swelling, disrupted axon terminal patterning, and overall shorter body length in comparison to wild type zebrafish at similar stage in development (Bhattacharya et al. unpublished).

\section{PTH2R}

PTH2R was first identified in humans through its sequence similarity to PTH1R and ability to be stimulated by PTH (Usdin et al. 1995). However, the capacity for PTH to activate PTH2R is not conserved across species (Hoare and Usdin, 1999; Usdin et al. 1999; Dobolyi et al. 2003). The endogenous PTH2R ligand, PTH2 (TIP39), produces a robust cAMP response in human and rodent PTH2R-expressing cell lines (Usdin et al. 1999). Activation selectivity against PTH and PTHLH is mediated by interactions between Tyr-318 of PTH2R with the 5th residues of these two ligands (Weaver et al. 2017). Mammalian PTH2 expression is detected at the subparafascicular area and medial paralemniscal nucleus in the adult brain (Dobolyi et al. 2003; Bago et al. 2009).

\section{Results}

\section{Synteny and phylogenetic analysis of pth2rb}

Several rounds of genome duplication events are responsible for the diversity of members in the parathyroid hormone gene family across extant vertebrates today. Zebrafish possess several duplicated paralogs that may be misidentified as 'novel' genes (Kang et al. 2004; Postlethwait, 2007). To identify the presence of a duplicate of zebrafish $p t h 2 r$, we searched the zebrafish genomic database for $p t h 2 r a$-like sequences and identified a putative coding region, si: dkeyp-4h4.1 (XP_017208978), that shared 74\% identity with zebrafish Pth2ra and 61\% identity with human PTH2R in BLAST-aligned regions. 
Isolation of the pth2rb ORF was performed by reverse transcription on whole zebrafish RNA with reverse primers complementary to the predicted pth2rb 3' UTR. Initial reverse transcription experiments produced a non-translatable $p t h 2 r b \mathrm{cDNA}$, with several premature termination codons in the expected signal peptide-coding region of exon 2. 5' RACE from exon 2 revealed a novel in-frame signal peptide-coding exon, now exon 1 of si: dkeyp-4h4.1. Fulllength amplification of the intact pth2rb ORF was performed through PCR with forward and reverse primers complementary to the 5' and 3' UTRs. The amino acid sequence is shown aligned with all other human and Danio PTH receptors (Figure 1). Note that the receptor previously called PTH3R is encoded by ZFIN gene pthlrb and will thus be simply called PTH1Rb here, a name which better reflects the phylogeny (Table 1).

BLAST searches of the ENSEMBL zebrafish genomic database identify 13 exons of pth2rb on the reverse strand of chromosome 22 spanning contigs BX664720.7 and AL645755.2. By comparison, human PTH2R (NM_005048) also has 13 exons comparable to zebrafish pth2rb. Our previous work investigating the syntenic relationship between human and zebrafish coorthologs showed that zebrafish pth2ra on Dre9 has neighboring sequences shared with human PTH2R on Hsa2 (Catchen et al. 2009; Bhattacharya et al. 2011). A similar comparison with the ENSEMBL database against zebrafish $p t h 2 r b$ on Dre22 indicates syntenic regions on Hsa2. The pth2ra and pth2rb genes reside in paralogous chromosome segments between chromosomes Dre9 and Dre22 respectively (Figure 2). Phylogenetic analysis indicates that Pth2rb groups basal to other fish PTH2Rs and could be inferred to function similar to other PTH2Rs (Figure 3). We conclude that $p t h 2 r a$ and $p t h 2 r b$ have the properties of conserved synteny with the human genome and paralogy within the zebrafish genome as expected if the two genes arose in the teleost genome duplication event. 


\section{Evolutionary structural analysis indicates ligand binding site remodeling}

With two divergent forms of each receptor present in fish, we were able to investigate how the PTH1R and PTH2R groups have specialized at the structural level. All six PTH1R and PTH2R proteins from human and Danio are aligned in Figure 1. Overall conservation is high, especially in the 7-TM helix bundle and the ligand-binding ECD. When we shade the conserved residues at a 50\% level, 30 "split consensus" positions become apparent (green) at which PTH1R proteins and PTH2R proteins are each conserved within their group, but the groups have adopted different identities or different amino acid types. These split consensus cases offer a proxy for positions that are structurally/functionally important, but where a structural specialization has occurred between PTH1R and PTH2R. We sought to correlate these 30 positions with other features of the receptor. The alignment notes 21 ligand binding residues of PTH1R (asterisks), as defined by Ehrenmann et al. (2018). Most (13 of 21) of these ligand binding residues are perfectly conserved in the alignment, but 4 are split consensus residues, and another 8 are directly adjacent to split consensus residues. Most of the ligand binding residues fall into five concentrated clusters along the sequence, and all of those sequence segments include split consensus residues. The same is not true for the conserved intra-membrane polar network amino acids (the six residues in red in Figure 1; Ehrenmann et al. 2018), none of which are within 3 a.a. of a split consensus residue. The split consensus residues were mapped onto the PTH1R crystal structure in green in Figs. 4-5 (Ehrenmann et al. 2018). 90\% of the split consensus positions occur in the 7-helix bundle and loops, and 50\% occur along the segment TM6-ECL3-TM7, which forms one flank of the PTH binding pocket (arrow, Figure 4). ECL3 also has a PTH2Rspecific deletion of one aa. Figure 5 shows the orientations of those specialized side chains; most lie along the binding pocket. One notable switch is that PTH1R Y429, a key ligand binding 
residue in position to $\mathrm{H}$-bond with $\mathrm{PTH}$, is converted to a conserved His in PTH2R proteins.

Taken together, the results support a model in which the overall structure and signal transduction mechanism were maintained in vertebrate evolution while the lower PTH binding pocket was remodeled to provide for different ligand binding profiles in PTH1R vs PTH2R (see below).

\section{Developmental expression pattern has diverged in the pth $2 r$ paralogs}

To evaluate the expression of $p t h 2 r b$ we investigated the spatio-temporal distribution of pth2rb by whole mount in situ hybridization throughout development. Similar stages of development were also observed for expression of $p t h 2 r a, p t h 2$, and $p t h$ for comparison (Figure 6-8). The earliest $p t h 2 r b$ transcripts were observed accumulating in the blastula at 4 hrs postfertilization (hpf) (Figure 6B). At 12h, expression of $p t h 2 r b$ was detected during early segmentation throughout the developing central nervous system (CNS) (Figure 6C). During segmentation (17h-24h) pth2rb begins to primarily be expressed in the brain (Figure 6D, 6E). Through the hatching period (48h-72h), pth2rb becomes restricted to paired domains at the forebrain-midbrain regions (Figure $6 \mathrm{G}, 6 \mathrm{H}$ ). Coronal sections of the midbrain-forebrain boundary show pth2rb expression in paired domains in the ventral posterior tuberculum (PTv) (Figure 7I) at 2dpf. At 3dpf, pth2rb is observed across broader paired domains at the ventral posterior tuberculum (PTv) and the dorsal posterior tuberculum (PTd) (Figure 7J).

We found the expression patterns of the two paralogs pth2ra and pth2rb diverge sharply in later development. Both are expressed broadly throughout the CNS at early developmental stages, but pth2ra becomes restricted to the midbrain-hindbrain and otic vesicles at later stages (Figures $8 \mathrm{C}-8 \mathrm{~F}$ ), while $p t h 2 r b$ is expressed robustly at the forebrain-midbrain region (Figures 6G, 6H, 7I, 7J), in closer vicinity to pth2 and pthlb mRNAs (Figure 7C-7F) (Bhattacharya et al. 
2011). By 72 hpf, the pth2ra and pth2rb probes show distinct and non-overlapping patterns of high-expressing cells in the brain (Figures 6G, 6H vs. 8C-F).

\section{Pth2rb is a functional PTH2 receptor}

As members of the class B GPCR family, PTH receptors signal via the $\mathrm{G} \alpha_{\mathrm{S}}-\mathrm{cAMP}$ pathway. To analyze PTH2Rb stimulation in response to ligands PTH (1-34), PTHLH (1-36), and $\mathrm{PTH} 2$ relative to other parathyroid receptors, cAMP accumulation was measured via the GloSensor lucifase-based reporter assay. Transfected HEK293-derived (GS-22A) cells stably expressing zebrafish Pth2rb, zebrafish Pth2ra, human PTH1R, or human PTH2R were incubated with varying concentrations of ligand. Maximum luminescence (counts per second or $\mathrm{cps} \times 10^{-3}$ ) from receptor-dependent cAMP activity was measured following increasing concentrations of ligand exposure ([Ligand], Log (M)). Human PTH1R was observed to be stimulated by PTH (134) and PTHLH (1-36) (Figure 9A). PTH2 failed to produce strong cAMP accumulation with human PTH1R (Figure 9A). Human PTH2R showed a robust cAMP response to PTH2 exposure and near equivalent $\mathrm{E}_{\mathrm{Max}}$ when exposed to higher concentrations of PTH (1-34) (Figure 9B; Table 2). Zebrafish Pth2ra exhibited robust cAMP-dependent luminescence in response to PTH2 exposure and was stimulated by higher concentrations of PTH (1-34) and PTHLH (1-36) to relatively half the $\mathrm{E}_{\mathrm{Max}}$ observed from PTH2 (Figure 9C). Stimulation of Pth2rb by PTH2 displays approximately 10-fold and 2-fold $\mathrm{E}_{\mathrm{Max}}$ compared to zebrafish Pth2ra and human PTH2R respectively (Figure 9D). Pth2rb also was able to generate a lower cAMP response from PTH exposure, reaching an $\mathrm{E}_{\mathrm{Max}}$ to approximately half of that observed in human PTH1R and PTH2R. Thus, PTH2 is likely the primary ligand of zebrafish Pth2rb but does appear to be able to be partially stimulated by PTH (1-34) similar to Pth2ra. 


\section{Discussion}

In this study we have reported the cDNA cloning and characterization of a previously undescribed PTH2-sensitive class B GPCR in zebrafish, encoded by si: dkeyp-4h4.1. This is the $4^{\text {th }}$ and final member of the PTH receptor family in zebrafish, necessitating a change in gene names for this family. The $p t h 2 r$ gene should be designated $p t h 2 r a$, and the paralog described here should be renamed from si: dkeyp-4h4.1 to $p t h 2 r b$. The PTH receptor family in zebrafish is thus Pth1ra, Pth1rb (previously 3r), Pth2ra, and Pth2rb (Table 1). We note that the 1ra/b and 2ra/b designations do not reflect parallel evolutionary histories; the 1ra/b pair arose in an early event, perhaps the 2nd vertebrate whole genome duplication (Pinheiro et al. 2012), while the 2ra/b pair apparently arose in the 3rd, teleost-specific whole genome duplication. Zebrafish pth2rb locus exhibits syntenically conserved sequences with the human $P T H 2 R$ ortholog as well as with the zebrafish pth2ra paralog. This syntenic conservation indicates that $p t h 2 r b$ is likely an appropriate ortholog for inference of potential mammalian $P T H 2 R$ function.

Compared to Pth2ra, Pth2rb possesses a 56 a.a. insertion in the C-terminal intracellular domain (Figure 1). The presence of a relative insertion here is not Danio-specific; it is found across numerous species of ray-finned fishes, but its sequence conservation is weak. This extended C-terminus may allow for recruitment of additional GPCR accessory proteins to form complexes and further optimize or tune signaling, possibly through endosomal incorporation similar to that observed in PTH1R (Vilardaga et al. 2012; Bisello et al. 2004; Ferrandon et al. 2009; Culhane et al. 2015; Bockaert et al. 2003; Hall and Lefkowitz, 2002; Halls, 2018; Thompson et al. 2014).

In the sequence analysis (Figure 1) we sought use PTH1R/2R evolution to highlight, in an unbiased manner, potential sites of functional specialization. The ligand binding pocket, 
particularly at TM6-7, stands out as major site of remodeling early in chordate-vertebrate evolution (predating fish-mammal divergence) (Figures 4-5). Indeed, our analysis recovered three residues that were previously established by mutagenesis studies to provide discrimination between ligands. The TM7 segment $\mathrm{C}_{397} \mathrm{ELF}_{400}$ (hPTH2R numbering) has three split consensus residues; two of these $\left(\mathrm{C}_{397}\right.$ and $\left.\mathrm{F}_{400}\right)$ are responsible for PTH2R's ability to discriminate between the PTH and PTHLH ligands, as switching either one to the PTH1R form allows PTHLH to activate the receptor (Turner et al. 1998). The split consensus residue in TM3, L289 in PTH1R /I244 in PTH2R, also has this property (Bergwitz et al. 1997; Turner et al. 1998). As seen in Figure 5, L289 faces the ligand binding pocket, positioned such that the small steric change from L to I can alter the pocket. In similar mutagenesis experiments, Weaver et al. (2017) showed that PTH2R specificity for PTH2/TIP39 depends largely on its Y318 residue (matching PTH1R I363; arrowhead in Figure 1). Y318 did not meet our criteria for a split consensus residue because, interestingly, zebrafish Pth1rb shares the Tyr residue at this position with PTH2R, making its ligand binding pocket more "PTH2R-like". Zebrafish Pth1rb appears to have evolved to mimic Weaver's in vitro mutagenesis result, since Pth1rb can be activated by PTH2 10 -fold better than Pth1ra (Gensure et al. 2004).

Our analysis of pth2rb expression by in situ hybridization indicates that mRNAs are expressed very early in zebrafish embryos through $72 \mathrm{hrs}$ past fertilization. Zebrafish $p t h 2 r b$ expression is observed beginning at $4 \mathrm{hpf}$ throughout the early developing CNS and exhibits partial overlap with that observed for pth2ra, however mRNA levels appear to vary by $24 \mathrm{hr}$ between these paralogs. At $48 \mathrm{hpf}$ we observed that pth2rb mRNAs are restricted to the forebrain-midbrain region of the brain and no longer overlap with pth $2 \mathrm{ra}$ expression by $72 \mathrm{hpf}$. 
Pth2rb expression at $72 \mathrm{hpf}$ also appears to be present across a wider range of tissue at the forebrain versus the otic vesicles and adjacent nuclei expression of $p t h 2 r a$ in the hindbrain.

Further analysis of in situ coronal sections reveals that pth2rb mRNAs are expressed 3 dpf primarily in tissues at the developing dorsal thalamus (DT) and posterior tuberculum (PT). We also observe $p t h 2$ ligand mRNA expression in cells adjacent to $p t h 2 r b$ mRNAs at the PT at 2 dpf and 3dpf. In zebrafish, the forebrain region is involved with stress experience, memory, and social behavior (Stednitz et al. 2018; Huang et al. 2019). The zebrafish PT shares characteristics with the dopaminergic A9 and A12 neurons in the mammalian brain (Blin et al. 2008; Matsui and Sugie, 2017, Mueller et al. 2011). While mammals lack a direct counterpart to the posterior thalamus, prosomeres two and three of the mammalian forebrain give rise to homologous regions in development (Mueller and Wullimann, 2003; Mueller, 2012; Wullimann and Puelles, 1999). Zebrafish lack a complex isocortex but their dorsal thalamic region does spatially correspond to the isocortex in mammalian brains (Mueller, 2012; Lodato and Arlotta, 2015). The prevalence of $p t h 2 r b$ at the forebrain suggests that it may play a regulatory with pituitary associated genes such as pitx3, gnrh2, and shh during early development (Herzog et al. 2003). Additional functional investigation of $p t h 2 r b$ in zebrafish neural tissues or behavioral studies may provide further insight to regulation and development of mammalian central nervous system.

Functional analysis of cAMP stimulation in response to PTH ligands shows that Pth2rb differs from Pth2ra not just in expression pattern, but also in ligand bias. Like human PTH2R, zebrafish Pth2rb shows greater activation by PTH than PTHLH, while Pth2ra is activated by both PTH and PTHLH to similar extents. Pth2ra, Pth2rb, and human PTH2R all produce the most robust cAMP accumulation after treatment with PTH2, while human PTH1R is not activated by PTH2. Presentation of PTH2 to Pth2rb yields a maximal cAMP response over 10- 
fold greater than that observed in zebrafish Pth2ra and approximately 2-fold greater than human PTH2R. The large difference in cAMP response observed between Pth2ra and Pth2rb by PTH2 would indicate significant differences in binding efficacy, accessory protein interactions, Gprotein regulators, and other factors that mediate GPCR signaling. One mechanism that may be of particular interest is the ability of GPCRs to mediate G-proteins from endosomal complexes with their ligands. The endosomal internalization of these ligand-receptor complexes along with several accessory proteins have been observed previously in PTH1R signaling to promote sustained cAMP production (Daaka et al. 1998; Ferrandon et al. 2009; Vilardaga et al. 2009; Eichel and von Zastrow, 2018; Calebiro et al. 2009; Vilardaga et al. 2014; Tsvetanova et al. 2015). Endosomal incorporation in response to PTH2 exposure been previously reported in human PTH2R, but the full functional significance for endocytosis has remained unclear (Bisello et al. 2004). In some cases, endosomal GPCR activation allows for signaling to persist beyond initial ligand binding and may be used as a means of resensitization if the receptor can be reincorporated at the membrane (Tsvetanova et al. 2015). The extended C-terminal domain of zebrafish Pth2rb may be a point of interest to identify factors associated with GPCR-endosomal signaling such as GPCR-associated sorting protein (GASP) and endosome sorting complex required for transport (ESCRT) multi-protein (Whistler et al. 2002; Katzmann et al. 2001; Tsvetnova et al. 2015).

These results provide an initial characterization of the PTH2-sensitive receptor, Pth2rb, isolated in zebrafish and member of the parathyroid family of class B GPCRs. Identified through a genomic homology screen against zebrafish $p t h 2 r a$, Pth2rb displays an extended C-terminal domain. Observations from in situ hybridizations show that $p t h 2 r b$ likely has a role in early forebrain-midbrain development where it is expressed adjacent to tissues expressing $P T H 2$ and 
pth1b ligands. Pth2rb is able to produce a notably higher maximum cAMP response that than observed in Pth2ra when exposed to PTH2. Future study into the function and expression of Pth2rb will broaden our understanding of vertebrate PTH2 signaling. 

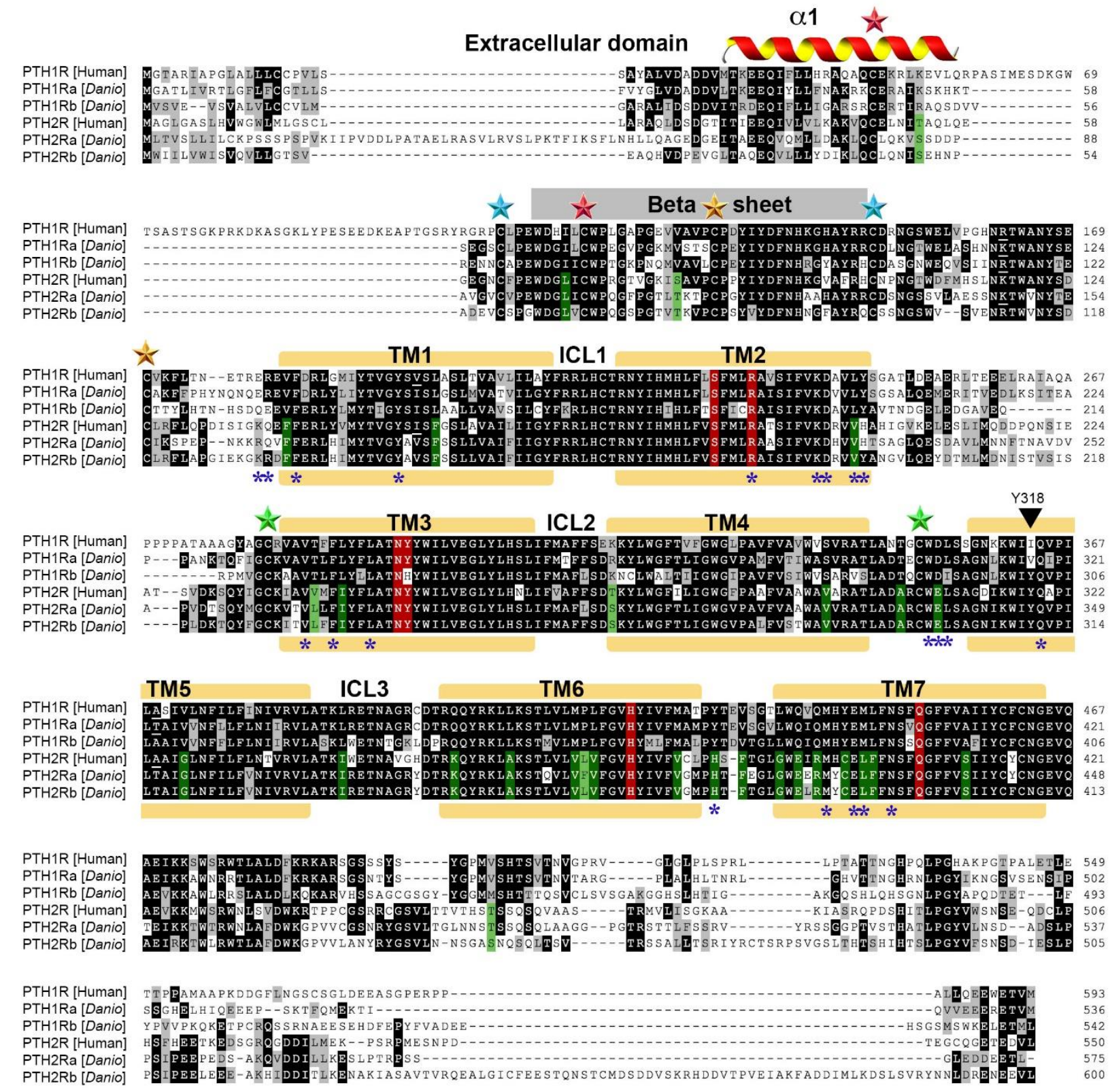

Figure 1. Alignment of Danio and Human PTHR family members. Major structural elements

(Pioszak \& Xu 2008; Ehrenmann et al. 2018) are indicated: The extracellular domain's alpha

helix 1 (helix icon) and beta sheet fold (gray bar); the seven transmembrane (TM) helices (TM1-

7, yellow bars); intracellular loops ICL1-3; and four pairs of disulfide bonded extracellular Cys

residues (individual disulfides indicated by color-matched pairs of stars). Main residues of the

TM bundle's intramembrane central polar network are highlighted red (Ehrenmann et al. 2018). 
Identities (black) and similarities (gray) are highlighted at a 50\% conservation level. At 30 positions the amino acid type is conserved within PTH1R and within PTH2R, but differs between them, indicating a conserved specialization of PTH1R vs. PTH2R. These "split consensus" residues are noted in dark green (if PTH1R and PTH2R have different identities) or light green (if PTH1R and PTH2R use different similarity groups). Only positions R162, V197, and A369 have two different residues at 50\% identity, but mixed across the PTH1R and PTH2R groups (indicated by white bars). The ligand binding residues discussed by Ehrenmann et al. (2018) are marked by an asterisk. Note that 19 of these 21 ligand binding residues lie near (within 4 a.a. of) a split consensus residue, indicating the ligand binding pocket has been customized in PTH1R vs. PTH2R. Arrowhead notes the ligand-discrimination residue Y318 in PTH2R (Weaver et al. 2017). 
A

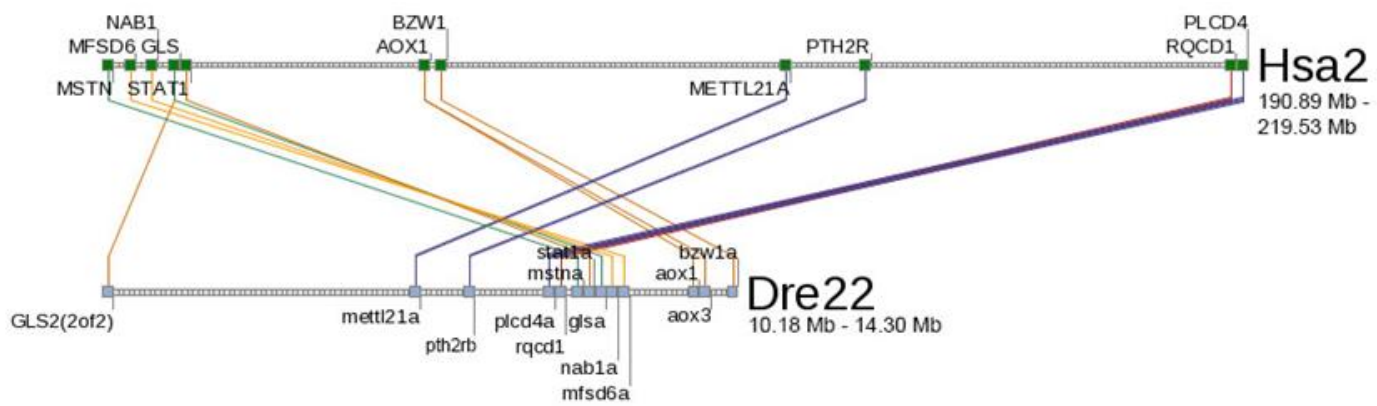

B

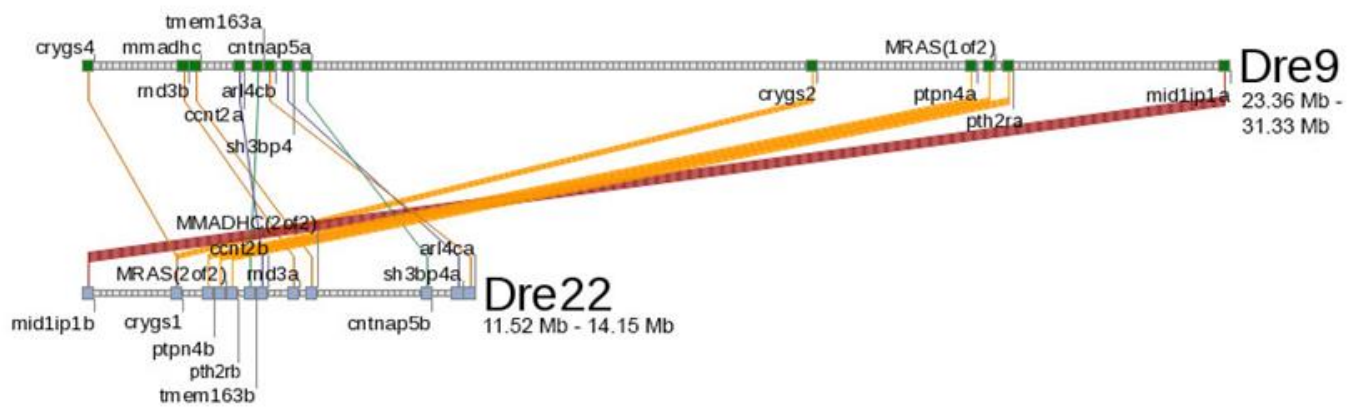

Figure 2. Syntenic analysis of pth2rb orthologs and paralogs. Comparison of neighboring genes between zebrafish $p t h 2 r b$ on Dre22 with human $P T H 2 R$ on Hsa2 (A) or zebrafish pth2ra on Dre9 (B). Green boxes indicate conserved orthologs or paralogs genes. White boxes indicate non-conserved peripheral genes. Colored connecting lines represent subclusters of neighboring genes. 


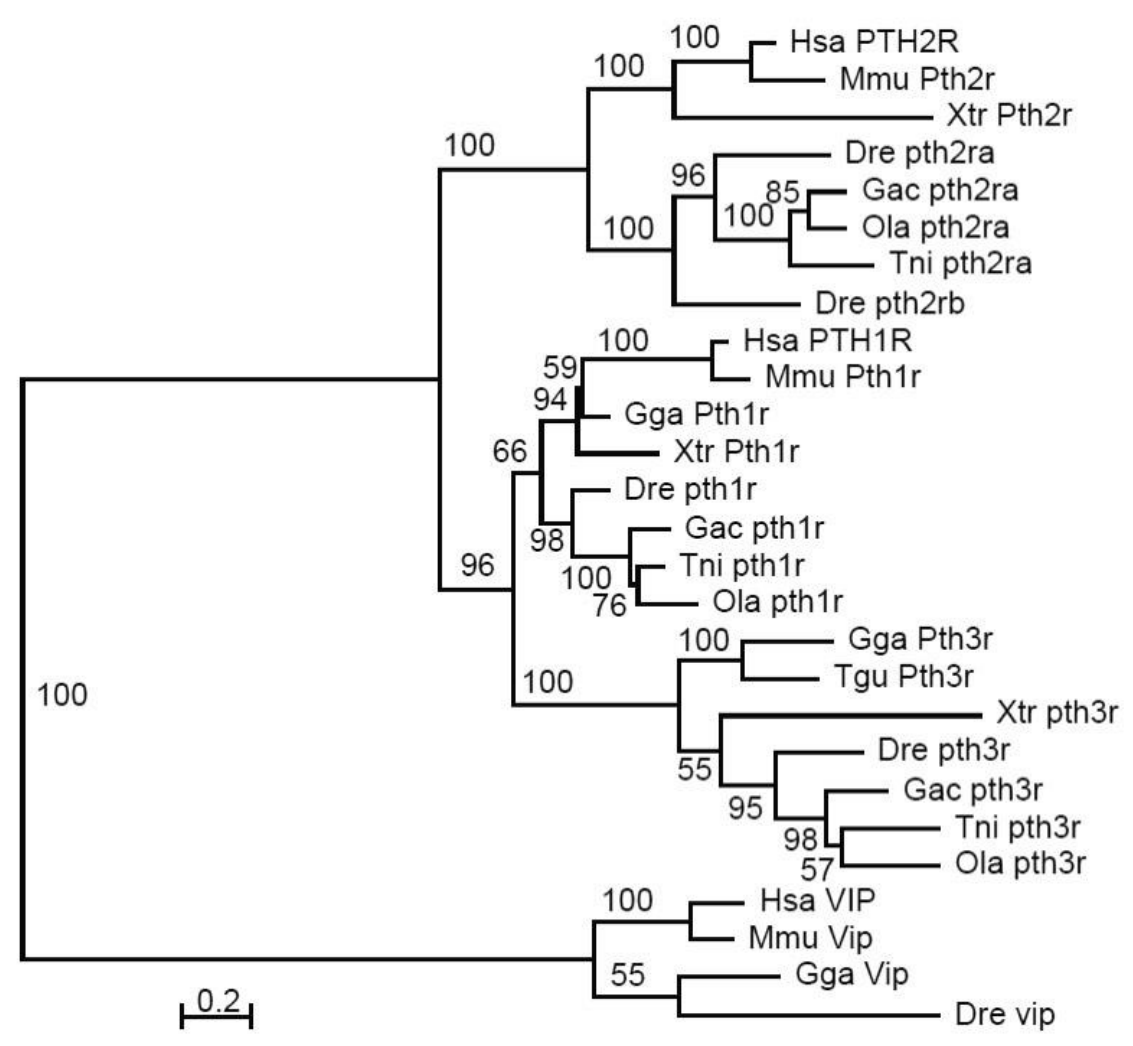

Figure 3. Phylogenetic analysis of PTH receptor family. Phylogenetic relatedness between PTH receptor orthologs across vertebrates with vasoactive intestinal peptide (VIP) genes as the outgroup. Top grouping with other PTH2R orthologs suggests $p t h 2 r b$ arose from a duplication event some point after the tetrapod-fish divergence. 


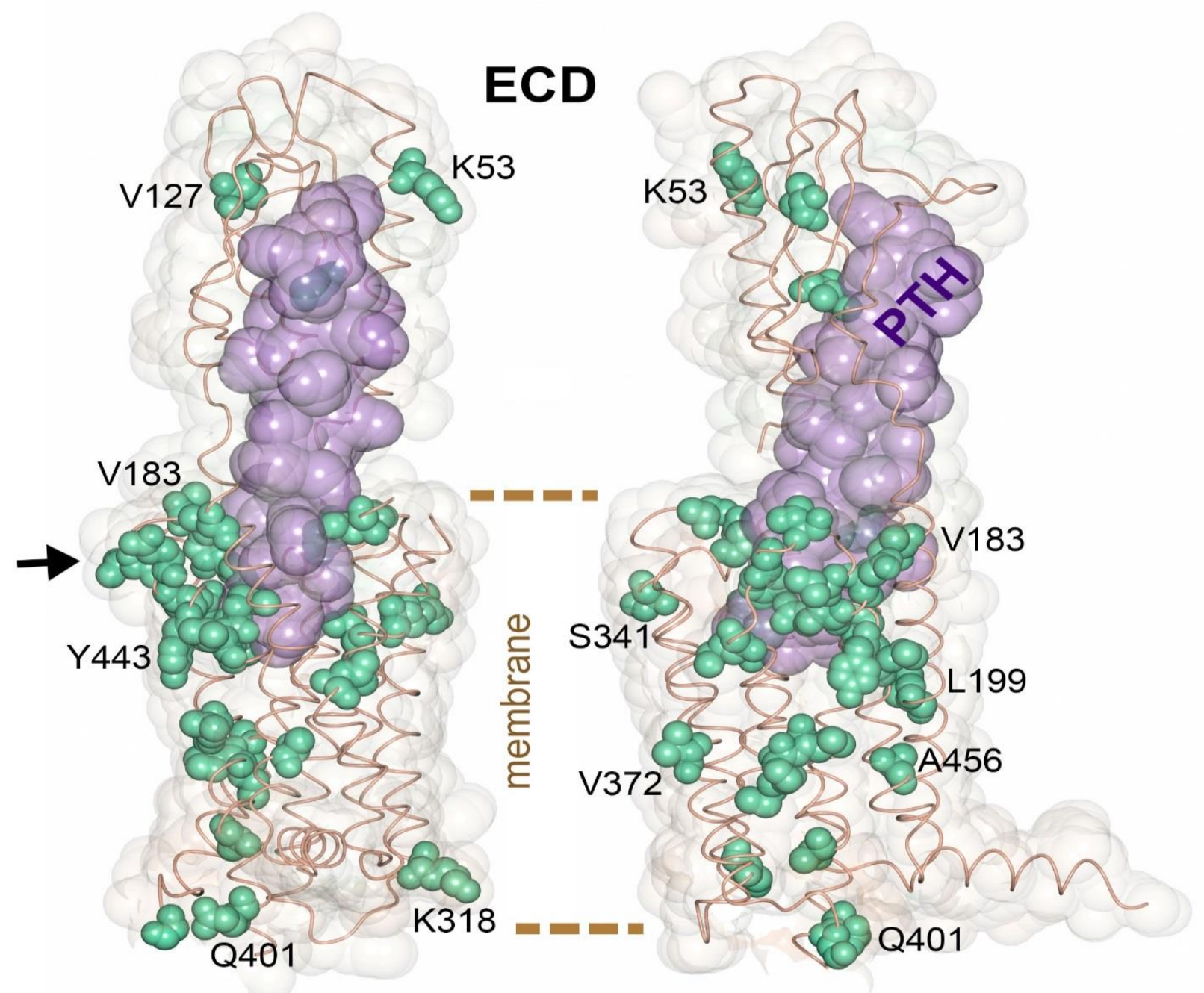

Figure 4. Crystal structure of PTH1R (PDB 6FJ3; Ehrenmann et al. 2018). The two views differ by a $\sim 90^{\circ}$ rotation around the long axis. The modified PTH hormone used in the crystal is shown surface-rendered in purple. Dotted lines indicate approximate position of the plasma membrane. The "split consensus" residues that are highlighted in green in Fig. 1 indicate points of intra-family conservation but inter-family divergence/specialization between PTH1R and PTH2R. Those residues are shown here in green sphere-rendering on the PTH1R backbone trace; select residues are labeled (PTH1R numbering). Note that this PTH1R/PTH2R specialization is particularly concentrated on one side of the intramembrane PTH binding pocket (arrow). 


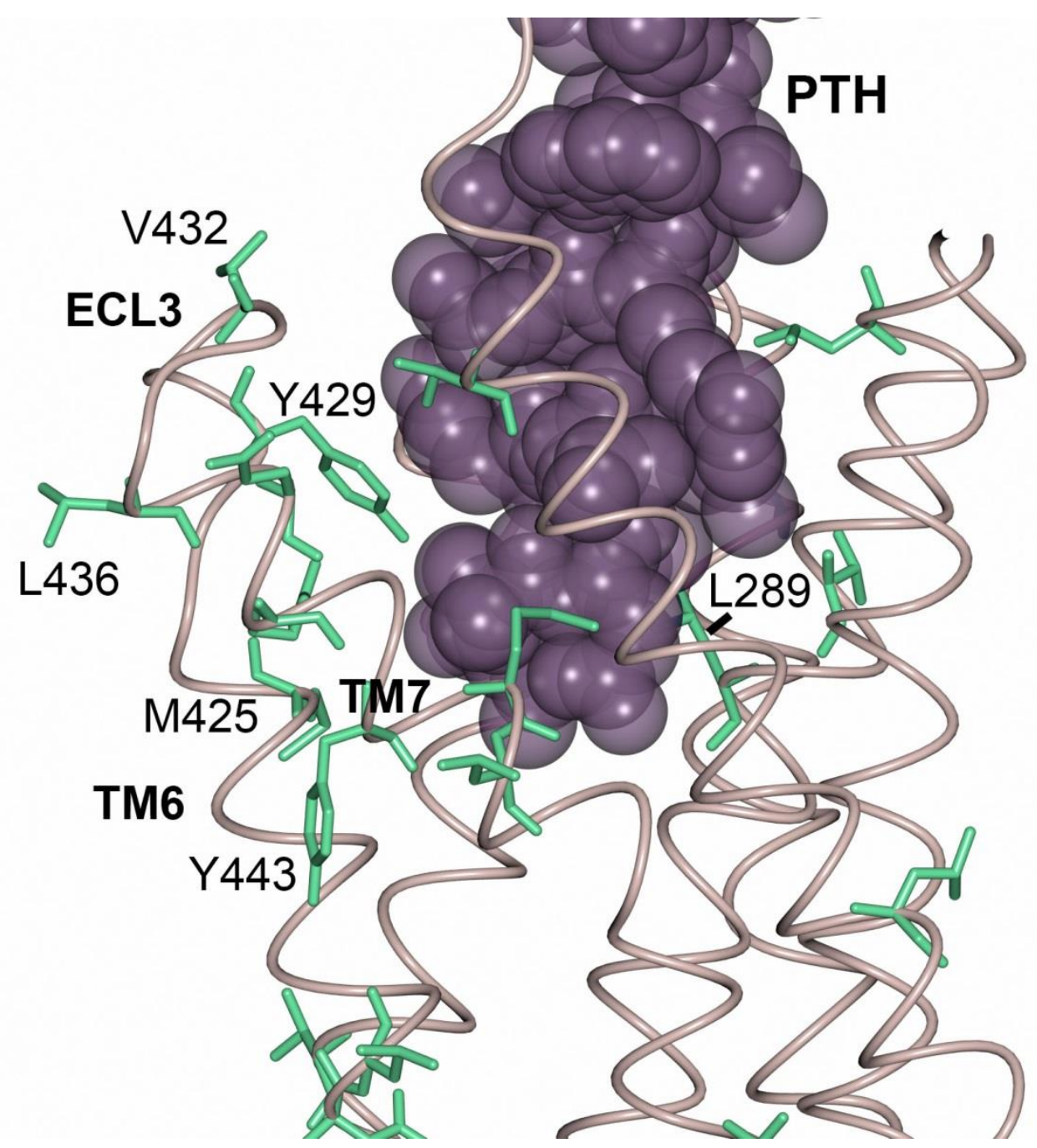

Figure 5. Close-up of PTH1R crystal structure (PDB 6FJ3; Ehrenmann et al. 2018). The region indicated by the arrow in Fig. 4 is shown, with the split-consensus residues in green cylinder-rendering and PTH with purple sphere-rendering. Most of the diverged side chains are in a position to potentially alter the PTH pocket surface. Ligand-discrimination residue L289 (I244 in PTH2R) is noted (Bergwitz et al. 1997; Turner et al. 1998). 


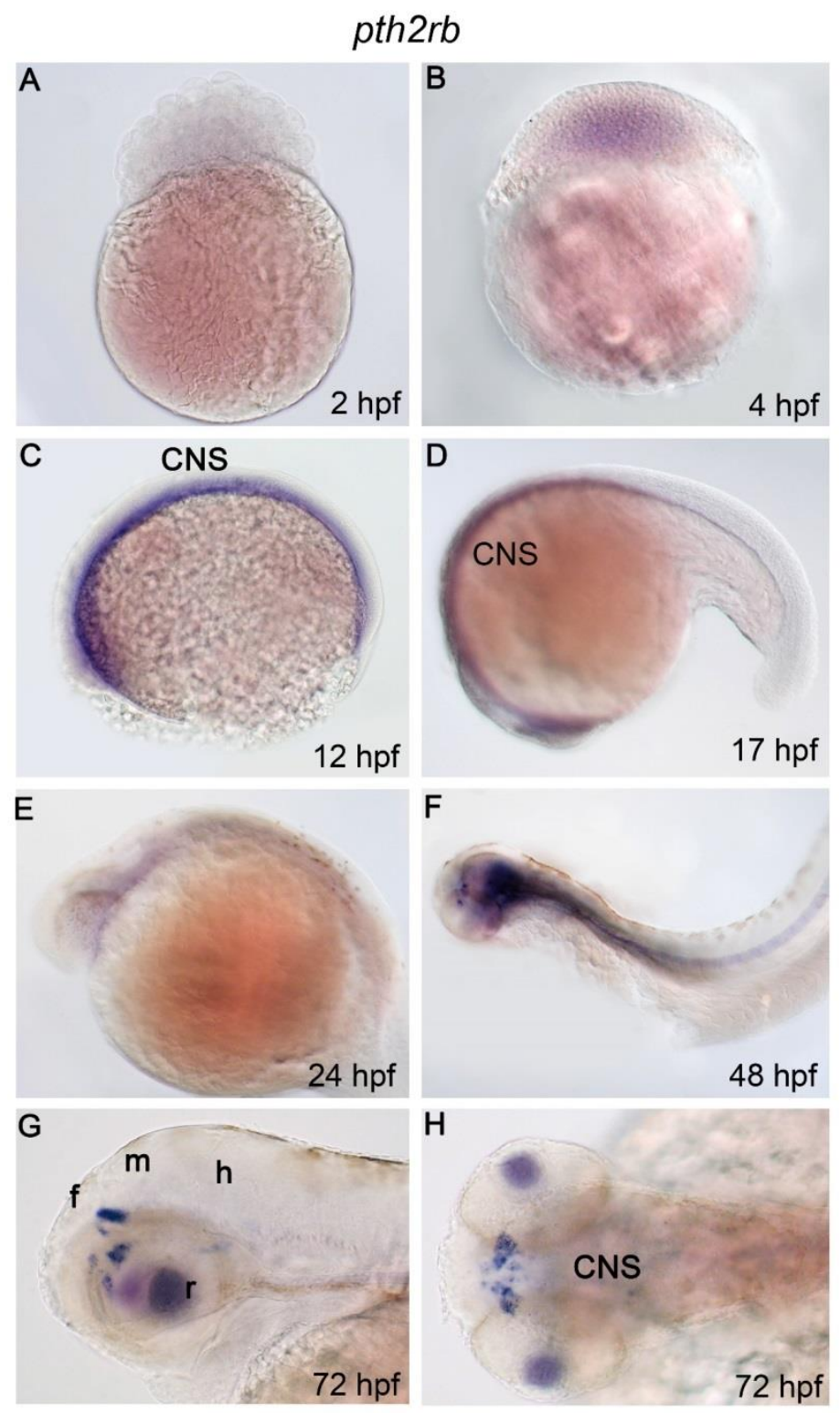

Figure 6. In situ hybridization detection of pth2rb. Detection of tissue-specific expression of pth2rb mRNA transcripts in whole mount in situ hybridization by cRNA probe. Pth2rb expression is observed in early cleavage through hatching period (A-H) in the CNS, forebrain (f), midbrain (m), hindbrain (h), retina (r), and notochord (no). Magnification of panel $\mathrm{G}$ and $\mathrm{H}$ are $2 \mathrm{X}$ of others. 


\section{Ligands}

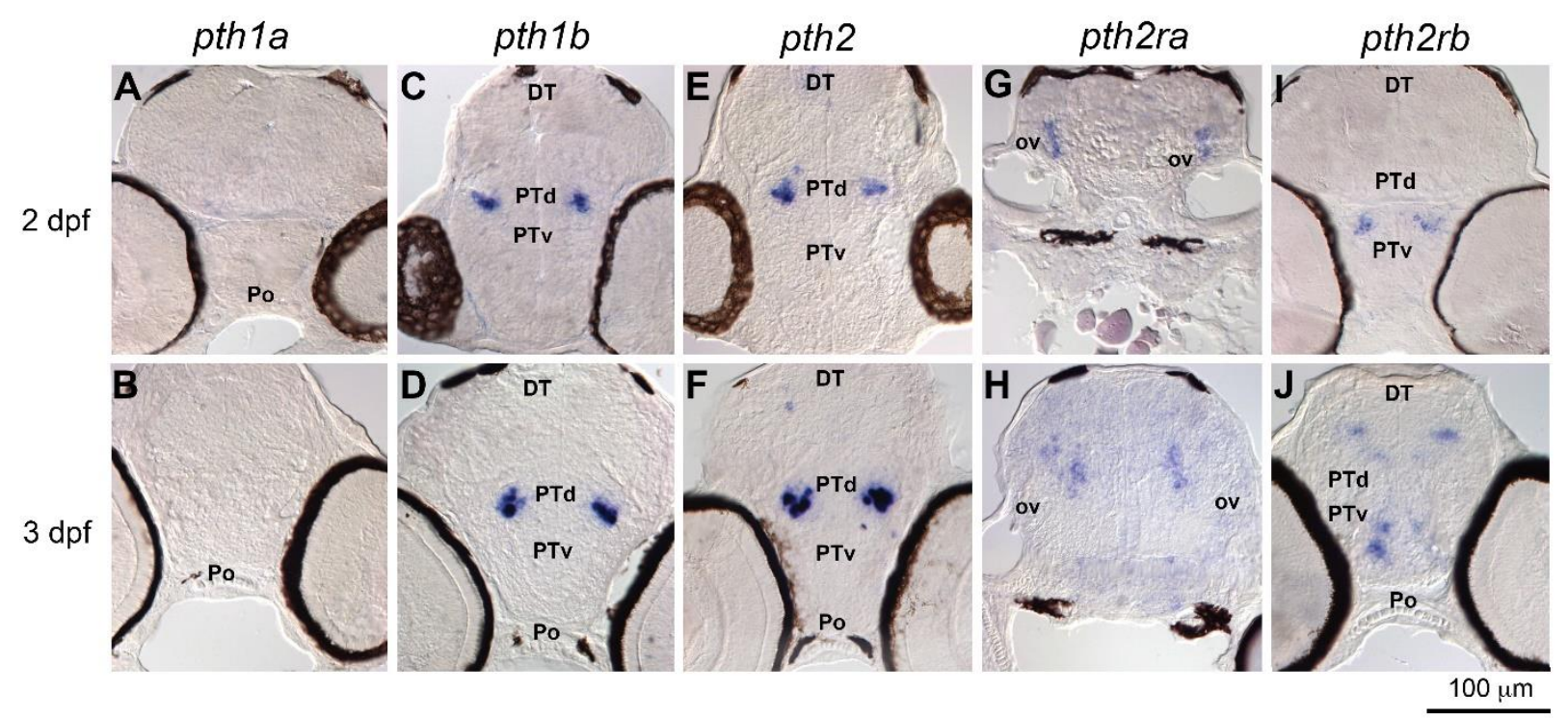

Figure 7. Coronal cryosections in situ hybridizations to detect pth ligands and receptors.

pthla is not detected in the brain at $2 \mathrm{dpf}$ or $3 \mathrm{dpf}(\mathrm{A}, \mathrm{B})$. pth $1 b$ is observed in paired domains in the dorsal posterior tuberculum (PTd) (C, D). pth2 is observed at $2 \mathrm{dpf}$ and $3 \mathrm{dpf}$ in the (PTd) (E, F) similar to pth1b. pth2ra is expressed $2 \mathrm{dpf}$ at the otic vesicles (ov) (G) and adjacent midbrain-hindbrain tissues at $3 \mathrm{dpf}(\mathrm{H})$. pth2rb is detectable at $2 \mathrm{dpf}$ at the ventral posterior tuberculum (PTv) (I) and (PTd) at 3dpf (J). DT: Dorsal thalamus, Po: Preoptic region 


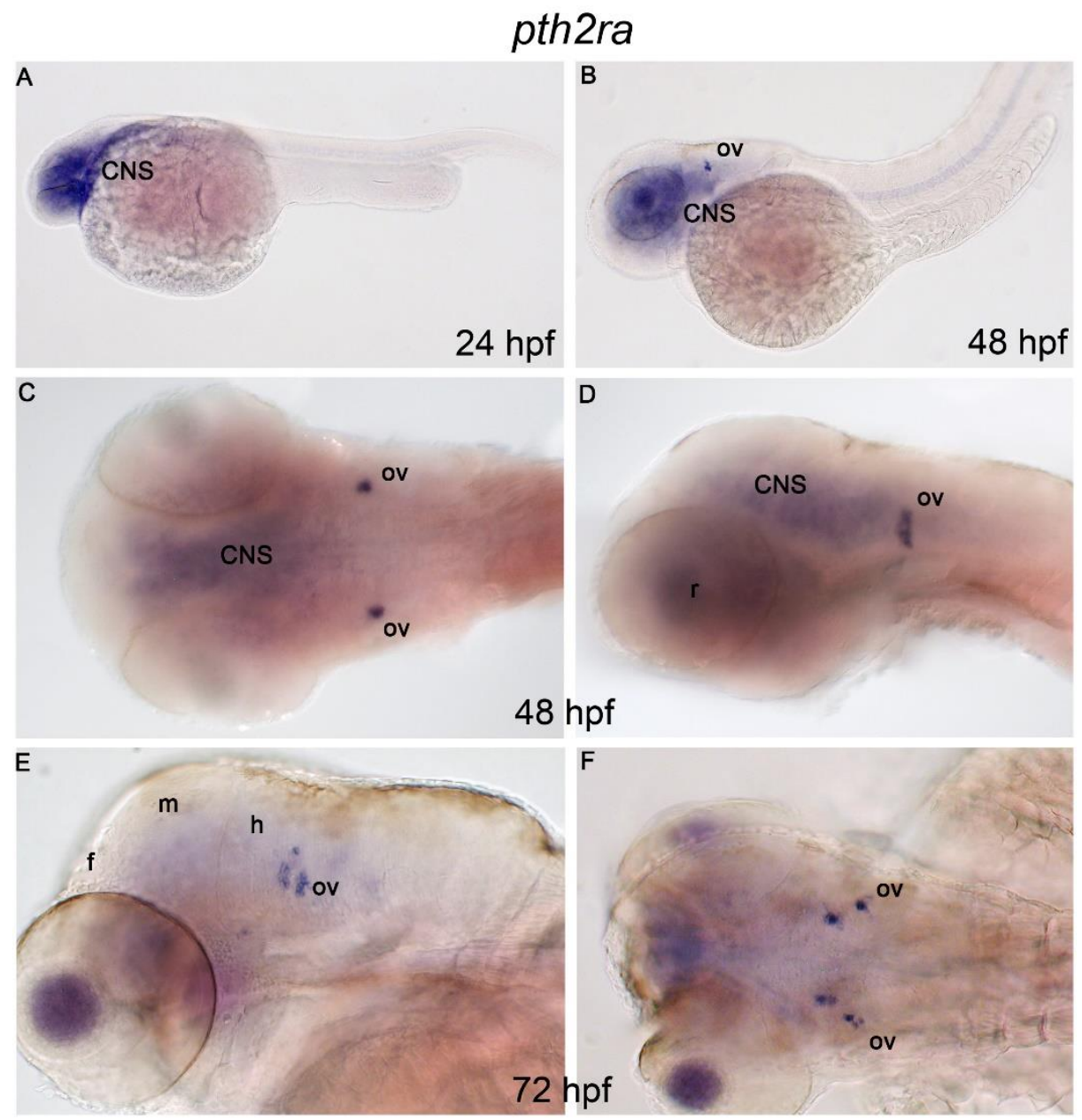

Figure 8. Whole mount in situ hybridization detection of pth2ra. Detection of zebrafish pth2ra mRNA transcripts by whole mount in situ hybridization. Pth2ra is strongly expressed throughout the brain at the pharyngeal period (A). Pth2ra expression becomes restricted to paired domains beginning at the hatching period in the otic vesicles (ov) and mid-hindbrain region (B-F). f: forebrain, m: midbrain, h: hindbrain. 

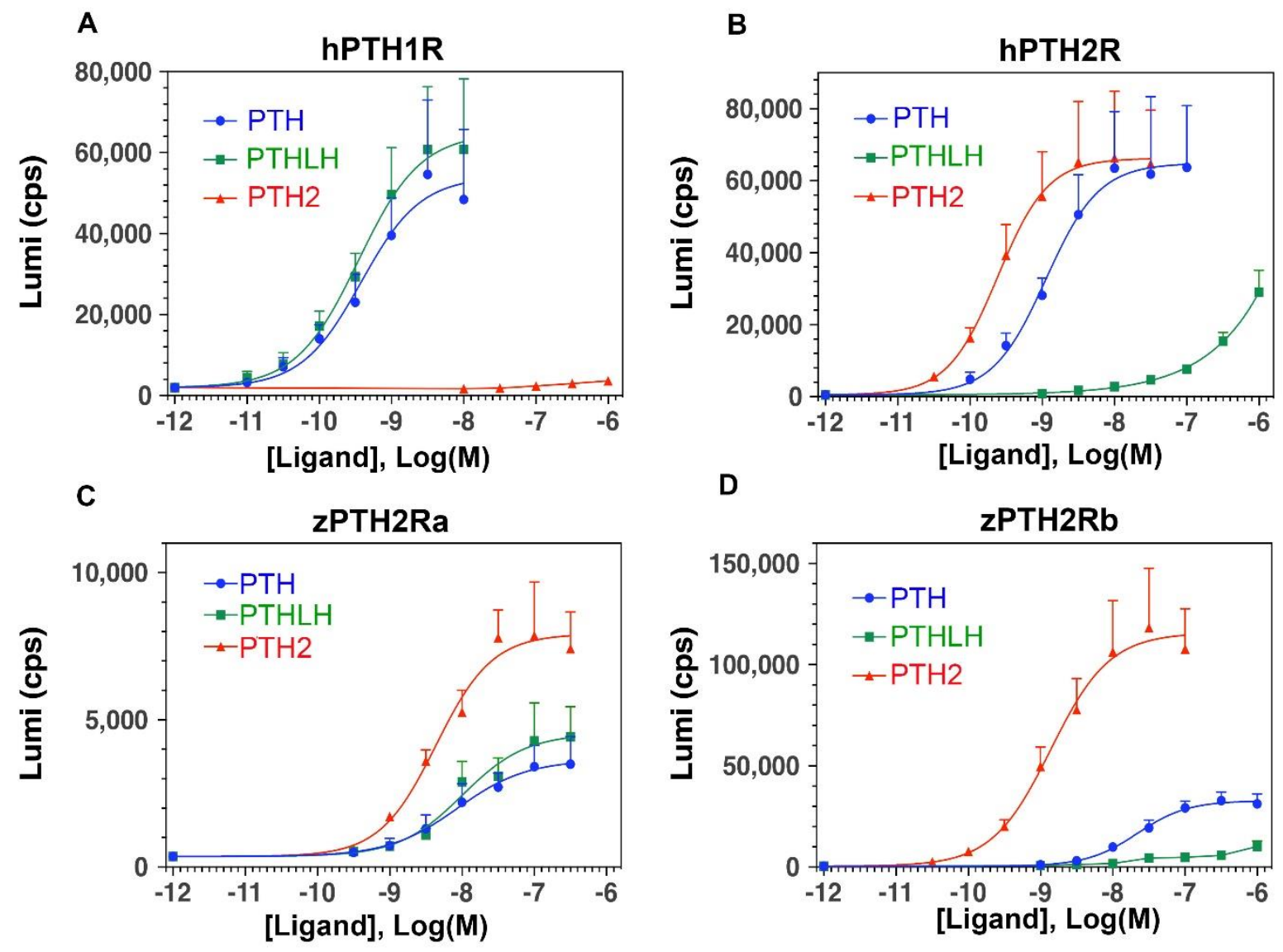

Figure 9. Evaluation of cAMP activity by PTH ligands. cAMP ligand-dose-response analysis of PTH (1-34), PTH2, or PTHLH (1-36) by HEK-293 cells stably transfected with luciferase based GloSensor reporter. cAMP signaling assessed in cells expressing either (A) human PTH1R (hPTH1R), (B) human PTH2R (hPTH2R), (C) zebrafish Pth2ra (zPTH2Ra), or zebrafish Pth2rb (zPTH2Rb). Data are expressed as means ( \pm SEM). Curves were fit to the data using a fourparameter, non-linear regression function. 


\section{Table 1}

Nomenclature of PTH ligands and receptors.

\begin{tabular}{ccc} 
Type & Earlier or preliminary name & Current or proposed name \\
\hline Danio gene & $z P T H 1 R$ & thlra \\
Danio gene & $z P T H 3 R$ & pth1rb \\
Danio gene & $p t h 2 r$ & pth2ra (proposed) \\
Danio gene & $s i:$ dkeyp-4h4.1 & pth2rb \\
PTH family hormone & TIP39 & PTH2 \\
PTH family hormone & PTHrP & PTHLH
\end{tabular}




\section{Table 2}

Measurements of GloSensor cAMP-dependent luminescence in transfected HEK-293 cells.

\begin{tabular}{|c|c|c|c|}
\hline Receptor & Ligand & $\mathrm{pEC}_{50}$ & $\mathrm{E}_{\text {MAX }}\left(\mathrm{CPS} \times 10^{-3}\right)$ \\
\hline \multirow[t]{3}{*}{ hPTH1R } & PTH (1-34) & $\begin{array}{c}9.48 \pm 0.13 \\
0.33 \mathrm{nM}\end{array}$ & $63 \pm 17$ \\
\hline & PTHLH (1-36) & $\begin{array}{c}9.58 \pm 0.13 \\
0.26 \mathrm{nM}\end{array}$ & $64 \pm 18$ \\
\hline & PTH2 & $\begin{array}{c}6.35 \pm 0.26 \\
446 \mathrm{nM}\end{array}$ & $5.1 \pm 1.0$ \\
\hline \multirow[t]{3}{*}{ hPTH2R } & PTH (1-34) & $\begin{array}{c}9.07 \pm 0.13 \\
0.85 \mathrm{nM}\end{array}$ & $66 \pm 18$ \\
\hline & PTHLH (1-36) & $\begin{array}{l}6.26 \pm 0.27 \\
546.26 \mathrm{nM}\end{array}$ & $61 \pm 25$ \\
\hline & PTH2 & $\begin{array}{c}9.69 \pm 0.10 \\
0.21 \mathrm{nM}\end{array}$ & $66 \pm 17$ \\
\hline \multirow[t]{3}{*}{ zPth2ra } & PTH (1-34) & $\begin{array}{c}7.97 \pm 0.23 \\
10.73 \mathrm{nM}\end{array}$ & $4.2 \pm 1.3$ \\
\hline & PTHLH (1-36) & $\begin{array}{c}8.17 \pm 0.14 \\
6.83 \mathrm{nM}\end{array}$ & $4.5 \pm 1.2$ \\
\hline & PTH2 & $\begin{array}{c}8.35 \pm 0.11 \\
4.46 \mathrm{nM}\end{array}$ & $8.3 \pm 1.3$ \\
\hline \multirow[t]{3}{*}{ zPth2rb } & PTH (1-34) & $\begin{array}{c}7.63 \pm 0.05 \\
23.69 \mathrm{nM}\end{array}$ & $33 \pm 4$ \\
\hline & PTHLH (1-36) & $\begin{array}{l}\text { n.d. } \\
\text { n.d. }\end{array}$ & $\begin{array}{l}\text { n.d. } \\
\text { n.d. }\end{array}$ \\
\hline & PTH2 & $\begin{array}{c}8.96 \pm 0.13 \\
1.11 \mathrm{nM} \\
\end{array}$ & $116 \pm 25$ \\
\hline
\end{tabular}

Table 3

P-values of zPth2rb vs. zPth2ra

\begin{tabular}{ccc} 
Ligand & $\mathrm{pEC}_{50}$ & $\mathrm{E}_{\mathrm{MAX}}\left(\mathrm{CPS} X 0^{-3}\right)$ \\
\hline PTH $(1-34)$ & 0.21 & 0.002 \\
PTHLH (1-36) & N.D. & N.D. \\
PTH2 & 0.008 & 0.013 \\
\hline
\end{tabular}




\section{CHAPTER II: PEZ}

\section{Introduction}

Protein tyrosine phosphatases (PTPs) are responsible for the removal of phosphates from tyrosine residues in proteins. The enzymatic tyrosine de-phosphorylation of PTPs acts opposite from protein tyrosine kinases (PTKs) that post-transcriptionally modify target proteins by attaching phosphates to tyrosine. The combination of phosphorylation and de-phosphorylation regulate signaling molecules, many of which are involved in cell cycle regulation, growth, differentiation, and protein turnover.

The PTP, Pez (PTPN14), was first isolated from human breast tissue in a screen for novel PTPs. The human form of Pez (PTPN14) is an 1187 residue protein with a molecular mass of $130 \mathrm{kDA}$ and can be broken into three functional $\mathrm{N}$-terminus, central linker, and $\mathrm{C}$-terminus (Smith et al. 1995). Drosophila Pez and its mammalian homologs PTPHD1/PTPN21 and PTPD2/PTP36/PTPN14 share similar structure in regard to their N-terminal FERM and Cterminal PTP domains, while their central linker regions show high amounts of variation (Smith et al. 1995; Edwards et al. 2001; Poernbacher et al. 2012). The N-terminal domain of Pez contains a 4.1, ezrin-radixin, moesin (FERM) domain that allows interface with the plasma membrane of the cell and elements of the cytoskeleton. As a regulatory element of the actin cytoskeleton, Pez forms complexes with focal adhesion kinase (FAK) and Src tyrosine kinase to promote cell motility in response to growth factors (Carlucci et al. 2008). At the cell membrane Pez is able to dephosphorylate Beta-catenin to stabilize cell-cell adhesions and form transient signaling complexes with epidermal growth factor receptor (EGFR) (Wadham et al. 2003; Carlucci et al. 2010; Roda-Navarro and Bastiaens, 2014). Pez overexpression has been associated with perturbations of the actin cytoskeleton, abated cell growth, and reduced focal 
adhesions (Ogata et al. 1999; Wadham et al. 2003; Wyatt et al. 2007). The lack of a signal sequence or transmembrane domain indicates that Pez does not directly embed into the membrane and remains cytoplasmic (Smith et al. 1995). The central linker domain contains proline-rich motifs resembling an $\mathrm{SH} 3$ domain and a WW domain that may also assist in Pez conformation in vivo (Smith et al. 1995). The presence of an N-terminal FERM domain and multiple protein interface motifs at the central linker domain suggest that Pez may act as a scaffold that promotes interactions between multiple other proteins.

The PTP domain of Pez would suggest that overexpression would lead to increased phosphatase activity on targets with phosphorylated tyrosine (pTyr). This predicted outcome is observed in Pez's interaction with Beta-catenin to stabilize cell-cell adhesions (Wadham et al. 2003). However, follicular cells of Drosophila embryos overexpressing Pez actually exhibit an increase of pTyr proteins. In affected follicle cells, Pez and pTyr aggregates can be detected at the apical membrane in close proximity by immunofluorescent antibodies. While Pez aggregates are observed at the apical membrane in follicle cells, they fail to bind several factors commonly associated there including: cadherin/catenin complex, actin, moesin, and spectrin. Ectopic Pez is shown to actually displace spectrin and F-actin at the apical membrane and coincides with adhesions forming between the oocyte and the apical membrane of follicle cells (Edwards, unpublished).

Absence of a kinase domain would suggest that at high levels Pez indirectly contribute to tyrosine phosphorylation likely by assisting activation of one or more kinases. The ability for Pez to act as a scaffold protein at the membrane may promote more kinase interactions with their targets at the apical membrane leading to the build-up of pTyr observed. If the activity of an individual PTK is responsible for the pTyr accumulation associated with ectopic Pez, we would 
expect that the knockdown of said PTK would result in an observable decrease in pTyr accumulation at the apical membrane. To identify PTK activity associated with Pez, we performed a knockdown screen in which RNAi lines targeting individual candidate PTKs were crossed to a line able to ectopically express Pez. The initial candidate PTKs to be knocked down were $A b l, A c k, C s k$, Shark, $\operatorname{Src42A}$, and $\operatorname{Src} 64 B$. These kinases were chosen for their association with establishment of cell polarity, apical membrane, oogenesis, or the Hippo pathway (Ferrante et al. 1995; Tamada et al. 2012, Hu et al. 2016; Kwon et al. 2015; Thomas and Wieschaus, 2004; Zandy et al. 2007). Our initial most likely candidate was $A b l$, the leukemia oncogene, which is expressed early on in egg chamber development, associates with F-actin, is found at the apical membrane. Abl's structure is often described as a 'clamp' that when inactive remains closed via an auto-inhibitory interaction between its $\mathrm{N}$-terminal $\mathrm{SH} 2 / \mathrm{SH} 3$ domains with its $\mathrm{C}$-terminal lobe regions. Unclamping of Abl via myristolation of its $\mathrm{N}$-terminus allows for conformational rearrangement which exposes its $\mathrm{SH} 3$ domain for potential interactions with the proline-rich central linker of Pez, which is a critical step for activating Abl's SH2 domain's kinase activity (Hantschel, 2012). Crosses allowed for the evaluation of pTyr accumulation in egg chamber follicle cells simultaneously expressing ectopic Pez and RNAi against a PTK via a clonal FLPout approach.

The possibility of two or more PTKs responsible for pTyr accumulation complicates this approach, as RNAi combinations to be expressed with ectopic Pez greatly increases the number of crosses performed and time to generate data. If no detectable inhibition of pTyr accumulation is observed in individual PTK RNAi cross this would indicate multiple PTKs are active at the apical membrane or an increase of PTK activity is not the mechanism behind the pTyr. 


\section{Results}

We searched the genome to identify all tyrosine kinases that could be targets of Pez. A total of 32 tyrosine kinase genes (excluding dual-specificity kinases) were identified by an exhaustive BLAST analysis of Drosophila coding regions using several known tyrosine kinases as "probes". The list does not include dual-specificity kinases. Kinases tested in this screen in bold. (-) represent low or no ovary expression based on RNA-seq data (Brown et al. 2014) (Table 1). Kinases that are not expressed in ovaries (flybase.org) were excluded from further consideration.

To produce flies in which Pez is clonally overexpressed along with loss of PTK expression, we generated the stock [Hsp70-FLP], [Act5C>CD2>GAL4]; [GMR-GAL4], [UASPez]; [UAS-mCD8-mCherry]. This line can be crossed to any UAS-RNAi stock, and the progeny assessed for differences in Pez or pTyr antibody staining. In this system, Hsp70 controls expression of FLP recombinase which can be 'turned on' by heat shock treatment. When expressed, the FLP recombinase excises the FRT-flanked CD2 spacer DNA upstream of GAL4, allowing for its expression via the cytoplasmic actin promoter. Accumulation of GAL4 in these clonal cells leads to activation of UAS-controlled CD8-mCherry RFP marking the clones, RNAi hairpin of the kinase knockdown line crossed, and Pez overexpression. Ovaries with UAS-Pez and UAS-TRiP RNAi elements were dissected from females $\sim 60 \mathrm{hr}$ post-heat shock to evaluate Pez and pTyr protein profiles. Pez and pTyr protein aggregates were observed using rabbit-antiPez and mouse-anti-pTyr antibodies detected by anti-rabbit-647 and anti-mouse-488 fluorescent antibodies respectively.

Confocal images were collected from stage 8-10 ovarioles from the UAS-Pez line crossed to kinase RNAi lines (Fig. 1). No visible decrease in pTyr co-localization with Pez was observed 
in $A b l$-RNAi (Fig.1A-F), Ack-RNAi (Fig. G-I), Csk-RNAi (Fig. 1J-L), Shark-RNAi (Fig. 1M-O), or Src64B-RNAi (Fig. 1P-R) lines. A decrease in pTyr was observed in RNAi knockdown of $\operatorname{Src42A}$ B-55868 (Fig. 2M-O \& S.2), that targets exon 1 of the Src42A-RA isoform (FBtr0335276) which contains an SH3 domain unique to this transcript. Two additional Src42A RNAi lines targeting Src42A-RA (B-02755 \& B-10817) (Fig. 2A-C \& 2P-R), failed to produce a visible difference in pTyr accumulation. Specific RNAi targeting Src42A-RB (Fig. 2D-F) or the shared conserved C-terminal domain of Src42A-RA/-RB (Fig. 2G-I) also did not appear to inhibit pTyr accumulation. The pTyr of junctions between clonal follicle cells and neighboring wildtype cells do not appear to be affected, however the increase of pTyr in clonal cells may make differences present difficult to resolve.

\section{Discussion}

To investigate the pTyr accumulation in cells overexpressing the Hippo pathway member, Pez, we observed effects of kinase RNAi on Pez overexpressing follicle cells. Our crosses simultaneously overexpressing Pez and cytoplasmic tyrosine kinase knockdowns indicate that one Src42A RNAi line (B-55868) was sufficient to visibly reduce pTyr accumulation in clonal follicle cells. This RNAi line specifically targets the Src42A-RA isoform, the gene's major transcript in adult females (flybase.org). However, two other lines targeting this isoform failed to visibly inhibit pTyr accumulation; this may be due to low efficacy RNAi knockdown.

The inability of additional Src42A RNAi lines to inhibit pTyr accumulation suggests that the specific 5'UTR of Src42A-RA targeted by B-55868 is the most effective at knocking down expression of this kinase. While some RNAi lines may show low or variable levels of suppression, all crosses of Src42A RNAi lines tested in our screen with ectopic Pez exhibit strong wing phenotypes when crossed to ms1096-GAL4 (not shown). The presence of these 
wing phenotypes makes the possibility of these other $\operatorname{Src} 42 \mathrm{~A}$ RNAi lines being inactive highly unlikely. A BLAST query with the 21-nt RNAi target sequence of B-55868 shows no significant identity with other transcripts in the Drosophila genome. There are no other matches of 20 or 21 bases, and just two matches of 19 bases (to couch potato and $S K$ ), neither of which has significant ovary expression. Thus, the pTyr inhibition observed is likely not a result of offtarget RNAi.

The hypomorphic nature of RNAi may provide difficult evaluation of the elevated pTyr levels exhibited by follicle cell expressing ectopic Pez. In the case of Pez overexpression, if a kinase's activity increased several fold compared to WT, incomplete knockout may be insufficient for visually detectable decrease in pTyr proteins. Therefore, while other RNAi lines could significantly decrease a given kinase's expression, the hyperactivity of any remaining kinase may make these RNAis appear ineffective when simply visualized. A quantitative approach measuring signal intensity, size, or abundance of pTyr aggregates may prove useful to determine knockdown effectiveness. However, these parameters vary with the stage of the egg chamber and age of the clone, making quantitation difficult in that tissue.

An alternative approach for kinase ablation could be through the popular CRISPR/Cas9 system to examine lines that can conditionally generate double stranded breaks (DSB) to target kinase genes. Flies that possess the UAS-Cas9 element and capable of conditional GAL4 expression can be crossed with flies expressing sgRNA for a specific kinase. Like our current kinase knockdown screen, GAL4 expression would generate clonal follicle cells that induce a kinase knockout mediated by Cas9-sgRNA.

Future work in better understanding apical pTyr accumulation will include detection of Src42A in cells overexpressing Pez. The ability to detect Src42A will allow us to determine the 
extent that Src42A can be knocked down by RNAi lines when compared to wild-type. Detection will also be helpful in determining if $\mathrm{Src} 42 \mathrm{~A}$ is being directly bound to Pez at the apical membrane or if it remains cytosolic. Unfortunately, a preexisting Src42A line with a detectable marker or epitope tag is not currently available and would have to be constructed. Three monoclonal antibodies derived from human Src42A (AFFN-SRC-1D2, 1E5, and 9C1) fail to show binding in a Src42A-specific pattern in Drosophila and would not be appropriate for this model.

Pez is a conserved PTP associated with regulation of the Hippo signaling pathway. Ectopic Pez expression in the Drosophila follicle cell model results in an unexpected increase of pTyr colocalized with Pez aggregates at the apical membrane. To determine if the activity of a PTK was responsible for pTyr accumulation we performed a screen in which we could observe follicle cells simultaneously expressing a PTK RNAi in the presence of ectopic Pez. Analysis of these PTK knockdown crosses indicates that RNAi targeting the 5'UTR of Src42A-RA isoform is sufficient to inhibit pTyr accumulation. This inhibition appears specific to this form as knockdown of $\operatorname{Src} 42 A-R B$ fails to produce a similar inhibition. This suggests that Src42A-PA is likely associating with Pez at the apical membrane where it can phosphorylate protein targets more frequently or is itself activated by Pez. Our observations on the pTyr relationship between Pez and knockdown of $\operatorname{Src} 42 \mathrm{~A}$ kinase indicates that $\operatorname{Src} 42 \mathrm{~A}$ may play an indirect role in the Hippo signaling pathway. 


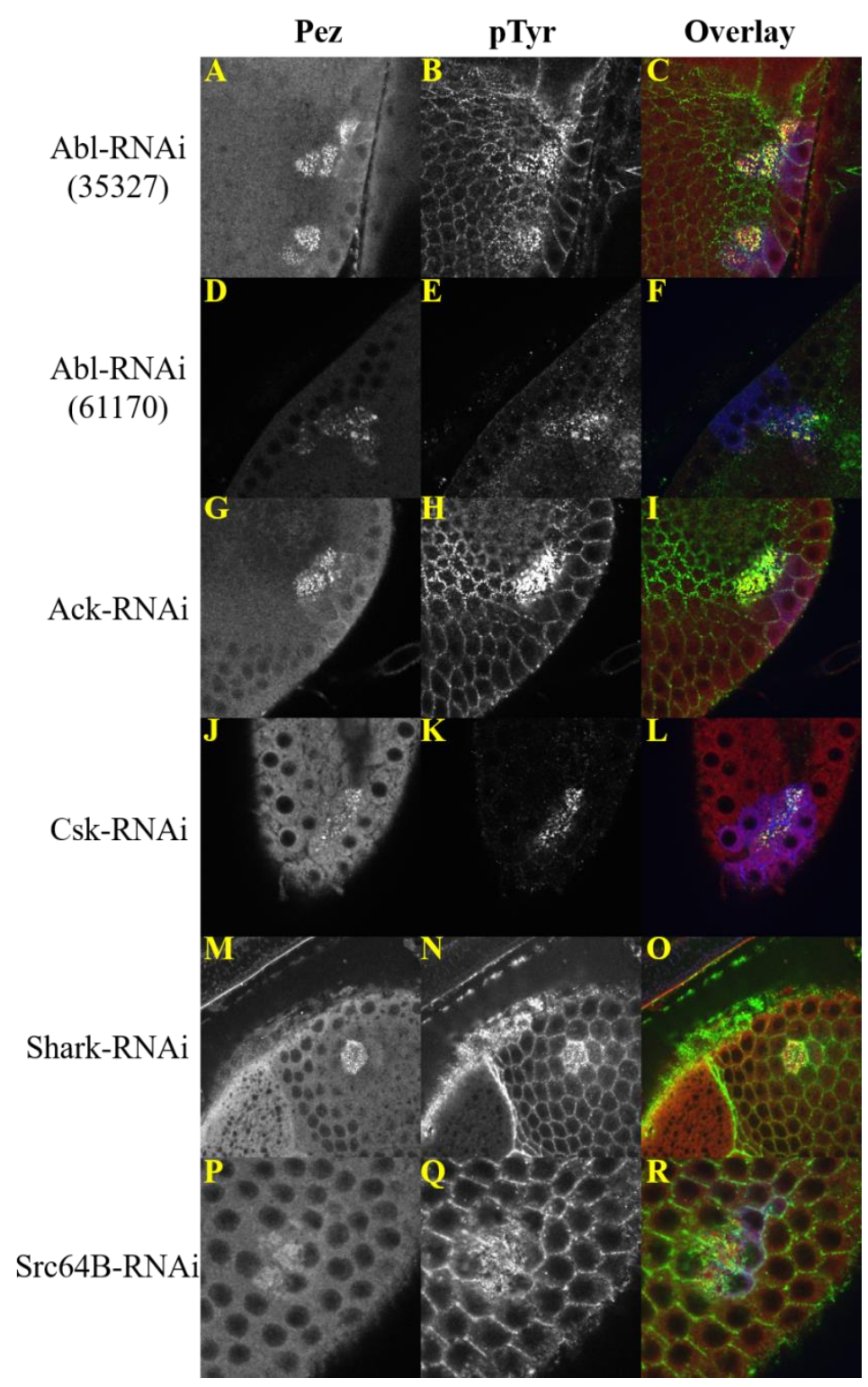

Figure 1. Accumulation of Pez and pTyr proteins in the presence of kinase RNAi. Pez overexpressing clonal follicle cells display Pez aggregates co-localized with pTyr proteins at the apical membrane. Secondary anti body detection of Pez and pTyr in UAS-Pez crossed to: AblRNAi BL35327 (A-C), Abl-RNAi BL61170 (D-F), Ack-RNAi (G-I), Csk-RNAi (J-L), SharkRNAi (M-O), Src64B-RNAi (P-R). Overlay of Pez (red), pTy (green), mCD8-RFP clone marker (blue). 


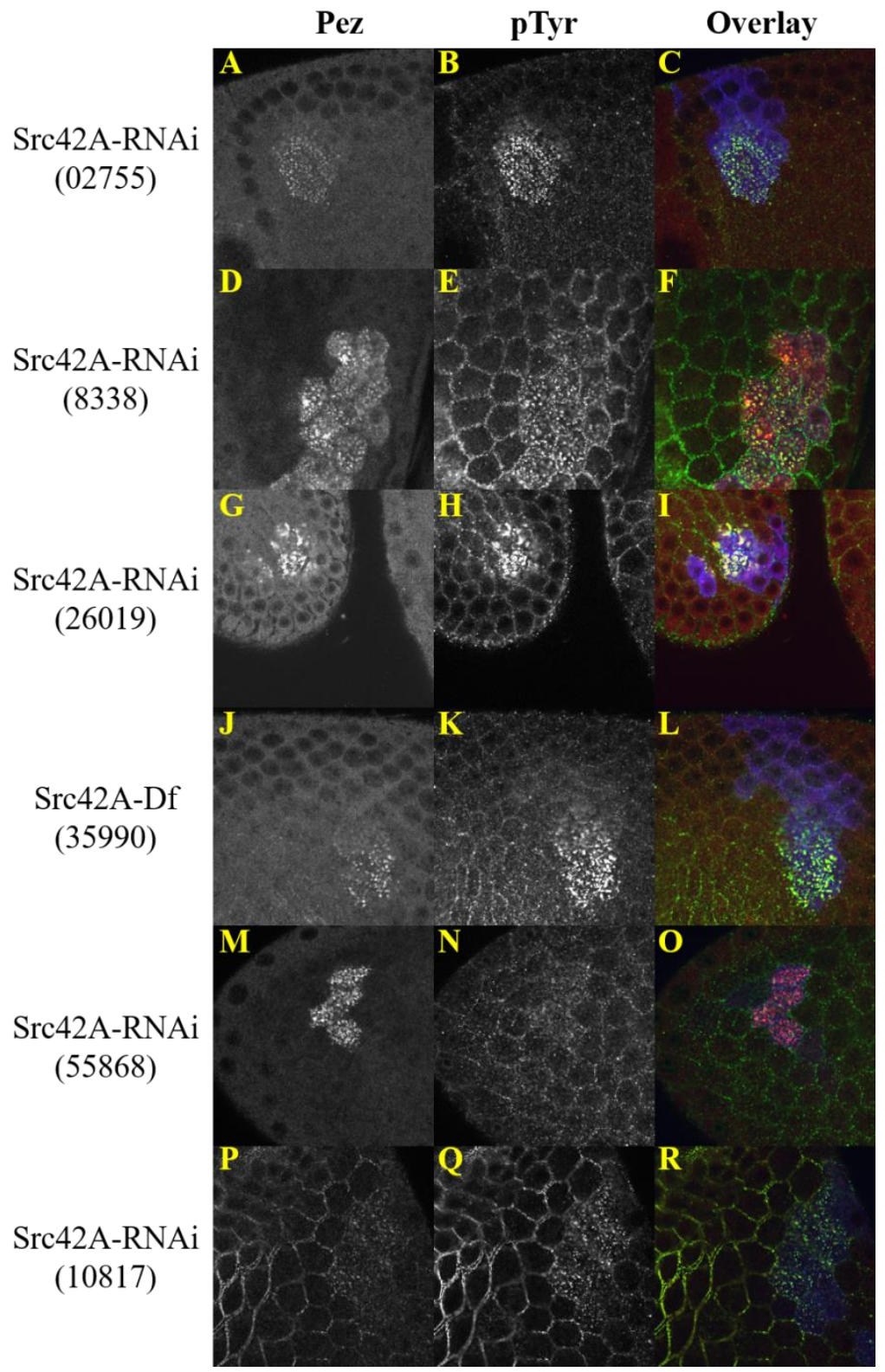

Figure 2. Accumulation of Pez and pTyr proteins in the presence of Src42A RNAi. Pez overexpressing clonal follicle cells display Pez aggregates co-localized with pTyr proteins at the apical membrane. Secondary anti body detection of Pez and pTyr in UAS-Pez crossed to: Src42A-RNAi 02755 (A-C), Src42A-RNAi 8338 (D-F), Src42A-RNAi 26019 (G-I), Src42-Df 35990 (J-L), Src42A-RNAi 55868 (M-O), Src42A-RNAi 10817 (P-R). Overlay of Pez (red), pTy (green), mCD8-RFP clone marker (blue). 


\section{Table 1}

Complete, nonredundant set of standard tyrosine-specific kinases in D. melanogaster.

\begin{tabular}{|c|c|c|c|}
\hline Abbreviation & Full gene name & CG number & FlyBase record \# \\
\hline Abl & Abl tyronsine kinase & CG4032 & FBgn0000017 \\
\hline Ack & Activated Cdc42 kinase & CG14992 & FBgn0028484 \\
\hline Ack-like & Activated Cdc42 kinase-like & CG43741 & FBgn0263998 \\
\hline Alk (-) & Anaplastic lymphoma kinase & CG8250 & FBgn0040505 \\
\hline Btk29A & Btk family kinase at 29A & CG8049 & FBgn0003502 \\
\hline Btl (-) & Breathless & CG32134 & FBgn0285896 \\
\hline Cad96Ca (-) & Cadherin $96 \mathrm{Ca}$ & CG10244 & FBgn0022800 \\
\hline CG3277 (-) & CG3277 & CG3277 & FBgn0031518 \\
\hline Csk & C-terminal Src kinase & CG42317 & FBgn0262081 \\
\hline $\operatorname{Ddr}(-)$ & Discoidin domain receptor & CG33531 & FBgn0053531 \\
\hline Dnt & Doughnut on 2 & CG17559 & FBgn0024245 \\
\hline Drl (-) & derailed & CG17348 & FBgn0015380 \\
\hline Drl-2 (-) & Derailed 2 & CG3915 & FBgn0033791 \\
\hline Egfr & Epidermal growth factor receptor & CG10079 & FBgn0003731 \\
\hline Eph & Eph receptor tyrosine kinase & CG1511 & FBgn0025936 \\
\hline Fak & Focal adhesion kinase & CG10023 & FBgn0020440 \\
\hline Fer $(-)$ & FER tyrosine kinase & CG8874 & FBgn0000723 \\
\hline Hop & hopscotch & CG1594 & FBgn0004864 \\
\hline htl & heartless & CG7223 & FBgn0010389 \\
\hline InR & Insulin-like receptor & CG18402 & FBgn0283499 \\
\hline Nrk (-) & Neurospecific receptor kinase & CG4007 & FBgn0020391 \\
\hline Otk (-) & Off-track & CG8967 & FBgn0004839 \\
\hline Pvr & PDGF- and VEGF-receptor related & CG8222 & FBgn0032006 \\
\hline $\operatorname{Ret}(-)$ & Ret oncogene & CG14396 & FBgn0011829 \\
\hline Ror (-) & Ror & CG4926 & FBgn0010407 \\
\hline Sev (-) & sevenless & CG18085 & FBgn0003366 \\
\hline Shark & $\mathrm{SH} 2$ ankyrin repeat kinase & CG18247 & FBgn0015295 \\
\hline Src42A & Src oncogene at $42 \mathrm{~A}$ & CG44128 & FBgn0264959 \\
\hline Src64B & Src oncogene at $64 \mathrm{~B}$ & CG7524 & FBgn0262733 \\
\hline Tie & Tie-like receptor tyrosine kinase & CG7525 & FBgn0014073 \\
\hline tor & torso & CG1389 & FBgn0003733 \\
\hline Wee1 & Wee1 kinase & CG4488 & FBgn0011737 \\
\hline Wsck & Wsck & CG31127 & FBgn0046685 \\
\hline
\end{tabular}




\section{Table 2}

Tyrosine kinase RNAi lines used for UAS-Pez cross.

\begin{tabular}{ccc} 
Kinase & Stock number & Location \\
\hline Abl & 35327 & BL \\
Abl & 61170 & BL \\
Ack & 33899 & BL \\
Csk & 41712 & BL \\
Shark & 25788 & BL \\
Src42A & 55868 & BL \\
Src42A & $44039 / 02755$ & BL \\
Src42A & $100708 / 108017$ & Vienna \\
Src42A & $17643 / 8338$ & Vienna \\
Src42A & $26019($ on 3$)$ & Vienna \\
Src42A & 35990 & BL \\
Src64B & 30517 & BL \\
\hline
\end{tabular}




\section{CHAPTER III: TOXICITY OF A FLYLIGHT GAL4 DRIVER \\ Introduction}

In Drosophila, the ability to spatially control gene expression allows for a broad range of studies. One effective method to manipulate gene expression is through the GAL4/UAS system (Fischer et al. 1988; Brand and Perrimon, 1993). In this system, the yeast transcription activator GAL4 can be expressed under the control of a cis-regulatory element (CRE) to act as a "driver" of gene expression in specific tissue. The upstream activation sequence (UAS) is the enhancer bound by GAL4 which recruits transcription factors to induce expression of downstream genes. The GAL4/UAS expression system is especially useful for misexpression studies as yeast GAL4 generally has little or no effect alone and UAS is absent or innocuous in Drosophila.

The Drosophila scalloped ( $s d$ ) gene plays a role in wing development. Scalloped is a Transcription Enhancer Factor-1/ AbaA Domain (TEAD) family DNA binding protein, first characterized by its mutant wing phenotype in 1929 (Gruneberg 1929; Campbell et al. 1992). Along with co-factors vestigial $(\mathrm{vg})$ and yorkie $(\mathrm{yki})$, Sd functions as a DNA sequence-specific transcription factor controlling cell proliferation in the developing wing (Williams et al. 1991). When associated with Yki, Sd acts to promote growth and proliferation via the Hippo pathway to affect multiple aspects in wing morphogenesis (Guss et al. 2001; Bandura and Edgar, 2008). Scalloped activity is also present in neuronal and muscle cells, where it assists in neuronal pathfinding (Guss et al. 2013; Corty et al. 2016).

A collection of GAL4 driver lines generated in the FlyLight Project at the Janelia Research Campus have been characterized by immunohistochemistry and computationally assigned to regions of the Drosophila brain (Pfeiffer et al. 2008; Jenett et al. 2012; Jory et al. 2012). Enhancer regions of 1,200 genes involved in the Drosophila brain were cloned with 
GAL4 coding region into a vector and then inserted into the fly genome (Pfeiffer et al. 2008). Insertion of these putative enhancer regions were mediated by a site-specific attP2 PhiC31 recombinase resulting in each enhancer inserted at the same genomic location, allowing for reliable comparison of expression patterns. (Groth et al. 2004; Pfeiffer et al. 2008; Jenett et al. 2012). This technique generated over 6,500 GAL4-driver lines including a line containing an enhancer/CRE region from approximately 2,200 bp of the first intronic region of $s d, s d^{R 94 B 03}$. GAL4 (w[1118]; P $\{\mathrm{y}[+\mathrm{t} 7.7] \mathrm{w}[+\mathrm{mC}]=$ GMR94B03-GAL4 $\}$ attP2 flybase.org/reports/FBti0139744)

Interestingly, $s d^{R 94 B 03}$-GALA displays a 'scalloping' phenotype at the edge of the adult wings even in the absence of a UAS associated gene element. GAL4-associated phenotypes have been previously reported in Drosophila, potentially due to a stress or immune response to high levels of GAL4 production (Kramer and Staveley, 2003; Bollepalli et al. 2017; Liu and Lehmann 2008). This wing phenotype suggests a disruption in wing morphogenesis during development by GAL4, despite expectations of no detectable phenotype when regulated by the majority of CREs.

Our preliminary work investigating $s d^{R 94 B 03}$-GALA wing scalloping has shown that caspase activity is detectable via the apoliner marker system (Edwards, unpublished) at the margins in $s d^{R 94 B 03}$-GAL4 pupal wing disc, indicating an increase in programmed cell death. This is a characteristic of mutations in $s d$ and other wing-margin mutants. Thus, $s d^{R 94 B 03}$-GAL4 wing scalloping could be due to either (A) toxic effects of excessive GAL4 protein, or (B) the $s d$ CRE fragment interfering with endogenous developmental genes. To further investigate the $s d^{R 94 B 03}$ GAL4 wing phenotype, we examined the cellular mechanism possibly responsible for an increase in caspase mediated cell death. 


\section{Results}

To evaluate whether the $s d^{R 94 B 03}$-GAL4 phenotype was due to GAL4 toxicity or a nonGAL4 mechanism, we examined if GAL80ts had any influence on wing scalloping. GAL80ts is a temperature sensitive protein that is able to inhibit GAL4 activity at low temperatures ( 18C), but itself becomes inactivated at higher temperature ( $\sim 30 \mathrm{C})$. A phenotypic reversion is seen in wings from GAL80ts/+; $s d^{R 94 B 03}$-GAL4/sd $d^{R 94 B 03}$-GAL4 flies raised at 21C compared to +/+; $s d^{R 94 B 03}-G A L 4 / s d^{R 94 B 03}-G A L 4$, and partial reversion in the same cross when raised at $25 \mathrm{C}$ (Fig. 1).

To determine if an increase in programmed cell death is responsible for scalloping, we examined the effects of the anti-apoptotic protein $\mathrm{p} 35$ in $s d^{R 94 B 03}$-GAL4 homozygotes. Inhibition of caspase activity is accomplished when cleavage of p35 itself causes a covalent binding to the caspase enzyme by p35 cleavage products to prevent further caspase activity (Bertin et al. 1996). The ectopic expression of $\mathrm{p} 35$ has previously been shown to partially suppress apoptosismediated loss of wing margin tissues (Krupp et al. 2005; Ellis et al 2018). The line, $P\left\{w^{+}, U A S\right.$ p35.H\}BHI was used to express p35 under control of $s d^{R 94 B 03}$-GAL4. Wings taken from $p 35 /+$; $s d^{R 94 B 03}-G A L 4 / s d^{R 94 B 03}-G A L 4$ exhibit a reversion of margin scalloping, although this phenotype does not appear identical to that seen in crosses with GAL80ts (Fig. 1). Differences between phenotypes may be due to ectopic expression p35, as endogenous caspase activity is required for proper development of margin tissues (Krupp et al. 2005; Jafar-Nejad et al. 2006).

The wing scalloping pattern of $s d^{R 94 B 03}$-GAL4 is similar to some loss-of-function phenotypes of Notch signaling, which contributes to wing vein patterning, cell proliferation, and margin formation (de Celis and García-Bellido, 1994; Mahoney et al., 2006). To investigate if the activity of the Notch pathway was disrupted, we used the line, $P\left\{w^{+}, N R E-E G F P . S\right\} 5 A$, 
which expresses GFP under the control of a Notch Response Element (NRE). Third instar $N R E /+;+/+, N R E /+; s d^{R 94 B 03}$-GAL4/TM6, and NRE/+; sd $d^{R 94 B 03}{ }_{-} G A L 4 / s d^{R 94 B O 3}$-GAL4 larvae wing discs were compared for differences in GFP Notch reporter signal. Notch activity is detected at the dorsal-ventral (DV) boundary in all three crosses (Fig. 3A-C). Punctate GFP reporter punctate can be observed at the wing DV boundary in NRE/+; $s d^{R 94 B 03}-G A L 4 /+$ and $N R E /+$; $s d^{R 94 B 03}-G A L 4 / s d^{R 94 B 03}$-GAL4 (Fig. 3B \& 2C) likely resulting from the increased cell death in those genotypes.

\section{Discussion}

The GAL4/UAS binary expression system has proven to be a powerful and flexible tool for studying gene expression in Drosophila. While most GAL4 driver lines show no phenotype, a pronounced wing scalloping phenotype is observed in the $s d^{R 94 B 03}-G A L 4$ driver line.

Observations from $p 35 \mathrm{x} s d^{R 94 B 03}$-GAL4 crosses indicate that scalloping is due to an increase in programmed cell death at the developing wing disc margins. GAL80ts, which binds and inactivates GAL4, produces a strong reversion of the $s d^{R 94 B 03}$-GAL4 wing phenotype. This demonstrates that margin formation is disrupted by a UAS-independent GAL4 activity unique to this line.

However, the $s d$ gene fragment in the $s d^{R 94 B 03}$-GAL4 construct remained a possible contributor to the apoptotic effect, perhaps by affecting the regulation of local genes, or disrupting expression of the endogenous $s d$ gene. Therefore, in other experiments, the $s d^{R 94 B 03}$ GAL4 driver line was edited using the CRISPR/Cas9 system to replace the GAL4 coding region with its Neurospora analog QF2 to determine if the phenotypic effects are exclusive to GAL4 (Lin and Potter, 2016). Those flies have QF2 activity at the margin, but the margin is not 
scalloped (not shown). Thus, GAL4 activity is sufficient to trigger a strong apoptotic response in this line.

Observations in third instar larvae wing discs indicate that Notch expression at the DV is normal in $s d^{R 94 B 03}-$ GALA/TM6 or $s d^{R 94 B 03}-G A L 4 / s d^{R 94 B 03}-G A L 4$. Apoptosis is evident in NRE expressing cells, indicating that the GAL4 toxicity mechanism does not involve turning off Notch signaling. It remains to be determined which other pathways are impaired by GAL4. The very consistent, dosage-sensitive wing phenotype of $s d^{R 94 B 03}-G A L 4$ makes it possible to perform targeted or large-scale genetic screens that could identify this mechanism.

The yeast derived GAL4/UAS offers a convenient system for studying gene expression through its modularity. The commonly inert nature of GAL4 in most Drosophila cells allows for its expression while avoiding confounding phenotypes when a UAS element is absent. The wing scalloping phenotype of $s d^{R 94 B 03}$-GALA driver line demonstrates the importance of evaluating newly generated driver lines, as they may still result in unexpected phenotypic side-effects. 
A

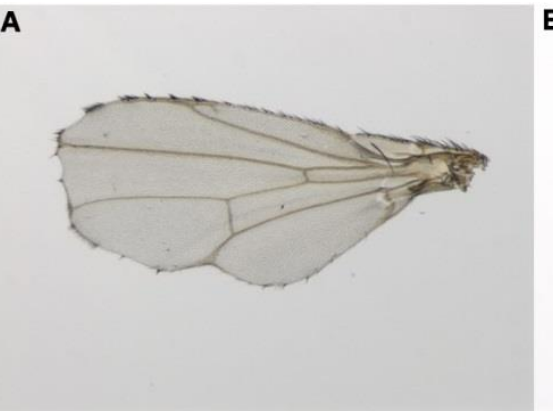

B

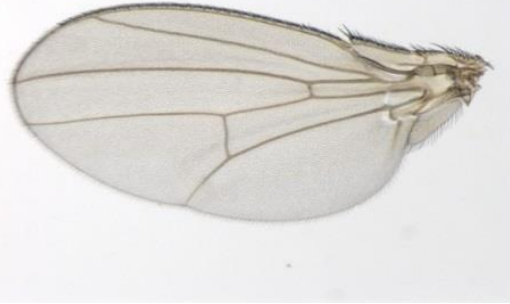

C

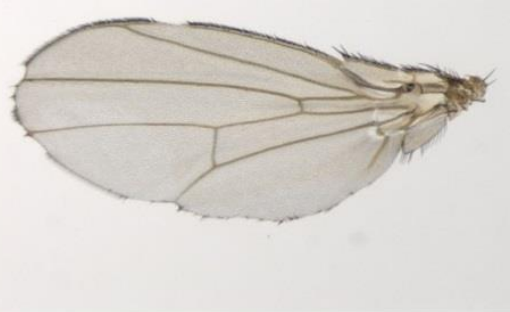

Figure 1. Wing phenotypes of GAL80ts crossed to $s d^{R 94 B 03}$ - GAL4. Wings from +/+; $s d^{R 94 B 03}$ $G A L 4 / s d^{R 94 B 03}{ }_{-} G A L 4$ raised at $21 \mathrm{C}(\mathrm{A}), G A L 80 t s /+; s d^{R 94 B 03}-G A L 4 / s d^{R 94 B 03}-G A L 4$ raised at $21 \mathrm{C}$ (B), and $G A L 80 t s /+; s d^{R 94 B 03}-G A L 4 / s d^{R 94 B 03}-G A L 4$ raised at $25 \mathrm{C}$.

A

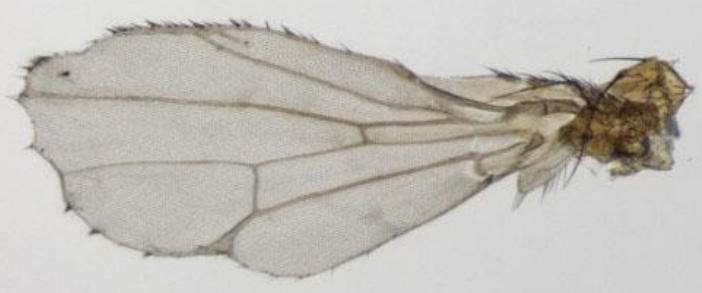

B

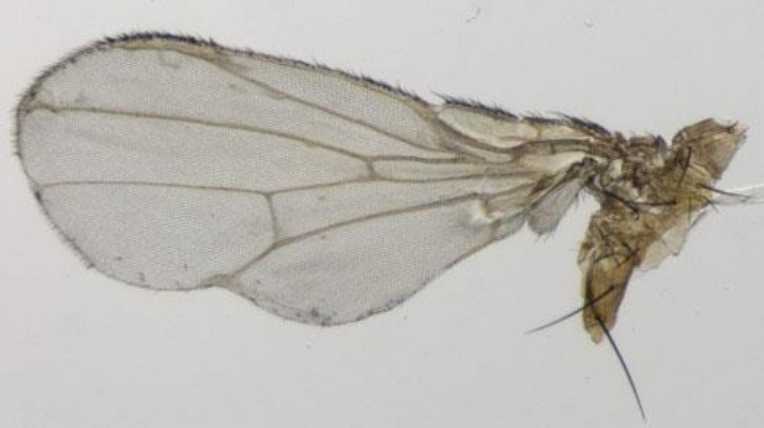

Figure 2. Wing phenotypes of UAS-p35 crossed to $s d^{R 94 B 03}$-GAL4. Wings from +/+; $s d^{R 94 B 03}$ $G A L 4 / s d^{R 94 B 03}{ }_{-} G A L 4$ (A) and $p 35 /+; s d^{R 94 B 03}-G A L 4 / s d^{R 94 B 03}-G A L 4$ (B) 

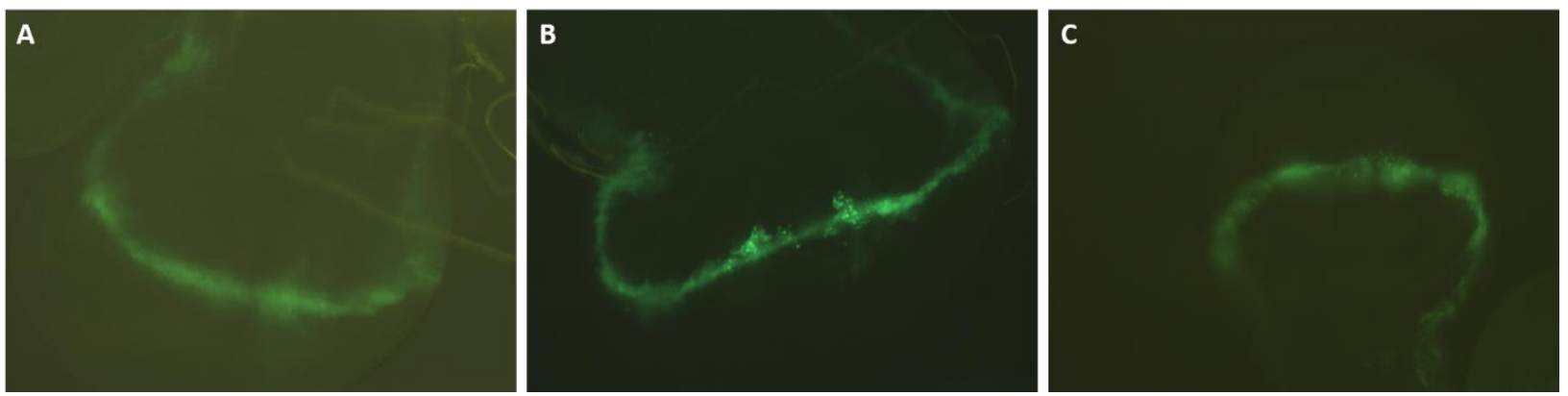

Figure 3. Detection of Notch GFP reporter. Wing discs from Notch GFP reporter $N R E /+;+/+$ (A) NRE/+; $\mathrm{sd}^{\mathrm{R} 94 \mathrm{~B} 03} / T M 6(\mathrm{~B})$ and NRE/+; $s d^{R 94 B 03}-G A L 4 / \mathrm{sd}^{\mathrm{R} 94 \mathrm{~B} 03}$. 


\section{REFERENCES}

\section{Pth2rb}

Åkesson, K., Tenne, M., Gerdhem, P., Luthman, H., \& McGuigan, F. E. (2015). Variation in the PTH2R gene is associated with age-related degenerative changes in the lumbar spine. Journal of Bone and Mineral Metabolism, 33(1), 9-15.

Balenga, N., Koh, J., Azimzadeh, P., Hogue, J., Gabr, M., Stains, J. P., \& Olson, J. A. (2019). Parathyroid-targeted overexpression of Regulator of G-Protein Signaling 5 (R GS5) causes hyperparathyroidism in transgenic mice. Journal of Bone and Mineral Research: The Official Journal of the American Society for Bone and Mineral Research.

Bhattacharya, P., Yan, Y. L., Postlethwait, J., \& Rubin, D. A. (2011). Evolution of the vertebrate pth2 (tip39) gene family and the regulation of PTH type-2 Receptor (pth2r) and its endogenous ligand pth2 by Hedgehog signaling in zebrafish development. The Journal of Endocrinology, 211(2), 187-200.

Bisello, A., Manen, D., Pierroz, D. D., Usdin, T. B., Rizzoli, R., \& Ferrari, S. L. (2004). Agonistspecific regulation of parathyroid hormone (PTH) receptor type 2 activity: structural and functional analysis of PTH- and tuberoinfundibular peptide (TIP) 39-stimulated desensitization and internalization. Molecular Endocrinology (Baltimore, Md.), 18(6), $1486-1498$.

Blin, M., Norton, W., Bally-Cuif, L., \& Vernier, P. (2008). NR4A2 controls the differentiation of selective dopaminergic nuclei in the zebrafish brain. Molecular and Cellular Neuroscience, 39(4), 592-604.

Bockaert, J., Marin, P., Dumuis, A., \& Fagni, L. (2003). The 'magic tail’ of G protein-coupled receptors: an anchorage for functional protein networks. FEBS Letters, 546(1), 65-72. 
Calebiro, D., Nikolaev, V. O., Gagliani, M. C., de Filippis, T., Dees, C., Tacchetti, C., ... Lohse, M. J. (2009). Persistent cAMP-signals triggered by internalized G-protein-coupled receptors. PLoS Biology, 7(8), e1000172.

Catchen, J. M., Conery, J. S., \& Postlethwait, J. H. (2009). Automated identification of conserved synteny after whole-genome duplication. Genome Research, 19(8), 1497-1505.

Cheloha, R. W., Watanabe, T., Dean, T., Gellman, S. H., \& Gardella, T. J. (2016). Backbone modification of a parathyroid hormone receptor-1 antagonist/inverse agonist. ACS Chemical Biology, 11(10), 2752-2762.

Chen, H., Han, X., Cui, Y., Ye, Y., Purrunsing, Y., \& Wang, N. (2018). Parathyroid Hormone Fragments: New Targets for the Diagnosis and Treatment of Chronic Kidney DiseaseMineral and Bone Disorder. BioMed Research International, 2018, 9619253.

Cheng, R.-K., Jesuthasan, S. J., \& Penney, T. B. (2014). Zebrafish forebrain and temporal conditioning. Philosophical Transactions of the Royal Society B: Biological Sciences, $369(1637)$.

Choi, H., Magyar, C. E., Nervina, J. M., \& Tetradis, S. (2018). Different duration of parathyroid hormone exposure distinctively regulates primary response genes Nurr1 and RANKL in osteoblasts. PloS One, 13(12), e0208514.

Colak, D., Ji, S.-J., Porse, B. T., \& Jaffrey, S. R. (2013). Regulation of axon guidance by compartmentalized nonsense-mediated mRNA decay. Cell, 153(6), 1252-1265.

Culhane, K. J., Liu, Y., Cai, Y., \& Yan, E. C. Y. (2015). Transmembrane signal transduction by peptide hormones via family B G protein-coupled receptors. Frontiers in Pharmacology, 6. 
Daaka, Y., Luttrell, L. M., Ahn, S., Rocca, G. J. D., Ferguson, S. S. G., Caron, M. G., \& Lefkowitz, R. J. (1998). Essential Role for G Protein-coupled Receptor Endocytosis in the Activation of Mitogen-activated Protein Kinase. Journal of Biological Chemistry, 273(2), 685-688.

Dimitrov, E. L., Kuo, J., Kohno, K., \& Usdin, T. B. (2013). Neuropathic and inflammatory pain are modulated by tuberoinfundibular peptide of 39 residues. Proceedings of the National Academy of Sciences of the United States of America, 110(32), 13156-13161.

Dobolyi, A., Dimitrov, E., Palkovits, M., \& Usdin, T. B. (2012). The neuroendocrine functions of the parathyroid hormone 2 receptor. Frontiers in Endocrinology, 3, 121.

Ehrenmann, J., Schöppe, J., Klenk, C., Rappas, M., Kummer, L., Doré, A. S., \& Plückthun, A. (2018). High-resolution crystal structure of parathyroid hormone 1 receptor in complex with a peptide agonist. Nature Structural \& Molecular Biology, 25(12), 1086.

Eichel, K., \& von Zastrow, M. (2018). Subcellular Organization of GPCR Signaling. Trends in Pharmacological Sciences, 39(2), 200-208.

Elli, F. M., Pereda, A., Linglart, A., Perez de Nanclares, G., \& Mantovani, G. (2018). Parathyroid hormone resistance syndromes - Inactivating PTH/PTHrP signaling disorders (iPPSDs). Best Practice \& Research. Clinical Endocrinology \& Metabolism, 32(6), 941954.

Ferrandon, S., Feinstein, T. N., Castro, M., Wang, B., Bouley, R., Potts, J. T., ... Vilardaga, J.-P. (2009). Sustained cyclic AMP production by parathyroid hormone receptor endocytosis. Nature Chemical Biology, 5(10), 734-742.

Gardella, T. J., \& Jüppner, H. (2001). Molecular properties of the PTH/PTHrP receptor. Trends in Endocrinology and Metabolism: TEM, 12(5), 210-217. 
Gardinier, J. D., Daly-Seiler, C., Rostami, N., Kundal, S., \& Zhang, C. (2019). Loss of the PTH/PTHrP receptor along the osteoblast lineage limits the anabolic response to exercise. PloS One, 14(1), e0211076.

Gellén, B., Zelena, D., Usdin, T. B., \& Dobolyi, Á. (2017). The parathyroid hormone 2 receptor participates in physiological and behavioral alterations of mother mice. Physiology \& Behavior, 181, 51-58.

Guerreiro, P. M., Renfro, J. L., Power, D. M., \& Canario, A. V. M. (2007). The parathyroid hormone family of peptides: structure, tissue distribution, regulation, and potential functional roles in calcium and phosphate balance in fish. American Journal of Physiology. Regulatory, Integrative and Comparative Physiology, 292(2), R679-696.

Guo, J., Khatri, A., Maeda, A., Potts, J. T., Jüppner, H., \& Gardella, T. J. (2017). Prolonged Pharmacokinetic and Pharmacodynamic Actions of a Pegylated Parathyroid Hormone (134) Peptide Fragment. Journal of Bone and Mineral Research: The Official Journal of the American Society for Bone and Mineral Research, 32(1), 86-98.

Hall Randy A., \& Lefkowitz Robert J. (2002). Regulation of G Protein-Coupled Receptor Signaling by Scaffold Proteins. Circulation Research, 91(8), 672-680.

Halls, M. L. (2018). Localised GPCR signalling as revealed by FRET biosensors. Current Opinion in Cell Biology, 57, 48-56.

He, S., Xue, M., Liu, C., Xie, F., \& Bai, L. (2018). Parathyroid Hormone-Like Hormone Induces Epithelial-to-Mesenchymal Transition of Intestinal Epithelial Cells by Activating the RuntRelated Transcription Factor 2. The American Journal of Pathology, 188(6), 1374-1388. 
Hogan, B. M., Danks, J. A., Layton, J. E., Hall, N. E., Heath, J. K., \& Lieschke, G. J. (2005).

Duplicate zebrafish pth genes are expressed along the lateral line and in the central nervous system during embryogenesis. Endocrinology, 146(2), 547-551.

Hong, A. R., Lee, J. H., Kim, J. H., Kim, S. W., \& Shin, C. S. (2019). Effect of Endogenous Parathyroid Hormone on Bone Geometry and Skeletal Microarchitecture. Calcified Tissue International.

Huang, L., Shum, E. Y., Jones, S. H., Lou, C.-H., Dumdie, J., Kim, H., ... Wilkinson, M. F. (2018). A Upf3b-mutant mouse model with behavioral and neurogenesis defects. Molecular Psychiatry, 23(8), 1773-1786.

Huang, V., Butler, A. A., \& Lubin, F. D. (2019). Telencephalon transcriptome analysis of chronically stressed adult zebrafish. Scientific Reports, 9.

Jaffrey, S. R., \& Wilkinson, M. F. (2018). Nonsense-mediated RNA decay in the brain: emerging modulator of neural development and disease. Nature Reviews Neuroscience, 19(12), 715.

Jia, K.-Z., Jin, S.-L., Yao, C., Rong, R., Wang, C., Du, P., ... Hua, Z.-C. (2017). Absence of PTHrP nuclear localization and C-terminus sequences leads to abnormal development of T cells. Biochimie, 138, 13-19.

Jolly, L. A., Homan, C. C., Jacob, R., Barry, S., \& Gecz, J. (2013). The UPF3B gene, implicated in intellectual disability, autism, ADHD and childhood onset schizophrenia regulates neural progenitor cell behaviour and neuronal outgrowth. Human Molecular Genetics, 22(23), $4673-4687$.

Jowett, T., \& Yan, Y. L. (1996). Double fluorescent in situ hybridization to zebrafish embryos. Trends in Genetics: TIG, 12(10), 387-389. 
Kang, J. S., Oohashi, T., Kawakami, Y., Bekku, Y., Izpisúa Belmonte, J. C., \& Ninomiya, Y. (2004). Characterization of dermacan, a novel zebrafish lectican gene, expressed in dermal bones. Mechanisms of Development, 121(3), 301-312.

Katzmann, D. J., Babst, M., \& Emr, S. D. (2001). Ubiquitin-dependent sorting into the multivesicular body pathway requires the function of a conserved endosomal protein sorting complex, ESCRT-I. Cell, 106(2), 145-155.

Lodato, S., \& Arlotta, P. (2015). Generating Neuronal Diversity in the Mammalian Cerebral Cortex. Annual Review of Cell and Developmental Biology, 31(1), 699-720.

Lykke-Andersen, S., \& Jensen, T. H. (2015). Nonsense-mediated mRNA decay: an intricate machinery that shapes transcriptomes. Nature Reviews Molecular Cell Biology, 16(11), $665-677$.

Magalhaes, A. C., Dunn, H., \& Ferguson, S. S. (2012). Regulation of GPCR activity, trafficking and localization by GPCR-interacting proteins. British Journal of Pharmacology, 165(6), $1717-1736$.

Mangin, M., Ikeda, K., Dreyer, B. E., Milstone, L., \& Broadus, A. E. (1988). Two distinct tumor-derived, parathyroid hormone-like peptides result from alternative ribonucleic acid splicing. Molecular Endocrinology (Baltimore, Md.), 2(11), 1049-1055.

Mantovani, G., \& Elli, F. M. (2019). Inactivating PTH/PTHrP Signaling Disorders. Frontiers of Hormone Research, 51, 147-159.

Matsui, H., \& Sugie, A. (2017). An optimized method for counting dopaminergic neurons in zebrafish. PLOS ONE, 12(9), e0184363. 
Miao, D., Su, H., He, B., Gao, J., Xia, Q., Zhu, M., ... Karaplis, A. C. (2008). Severe growth retardation and early lethality in mice lacking the nuclear localization sequence and Cterminus of PTH-related protein. Proceedings of the National Academy of Sciences of the United States of America, 105(51), 20309-20314.

Miao, Q., Li, J.-G., Miao, S., Hu, N., Zhang, J., Zhang, S., ... Wang, S.-W. (2012). The boneprotective effect of genistein in the animal model of bilateral ovariectomy: roles of phytoestrogens and PTH/PTHR1 against post-menopausal osteoporosis. International Journal of Molecular Sciences, 13(1), 56-70.

Mueller, T. (2012). What is the Thalamus in Zebrafish? Frontiers in Neuroscience, 6.

Mueller, T., Dong, Z., Berberoglu, M. A., \& Guo, S. (2011). The Dorsal Pallium in Zebrafish, Danio rerio (Cyprinidae, Teleostei). Brain Research, 1381, 95-105.

Mueller, T., \& Wullimann, M. F. (2003). Anatomy of neurogenesis in the early zebrafish brain. Brain Research. Developmental Brain Research, 140(1), 137-155.

Nishimori, S., Lai, F., Shiraishi, M., Kobayashi, T., Kozhemyakina, E., Yao, T.-P., ... Kronenberg, H. M. (2019). PTHrP targets HDAC4 and HDAC5 to repress chondrocyte hypertrophy. JCI Insight, 4(5).

Palma, P. F. S., Bock, C., Silva, T. S., Guerreiro, P. M., Power, D. M., Pörtner, H.-O., \& Canário, A. V. M. (2019). STC1 and PTHrP Modify Carbohydrate and Lipid Metabolism in Liver of a Teleost Fish. Scientific Reports, 9(1), 723. 
Panda, D. K., Goltzman, D., \& Karaplis, A. C. (2012). Defective postnatal endochondral bone development by chondrocyte-specific targeted expression of parathyroid hormone type 2 receptor. American Journal of Physiology. Endocrinology and Metabolism, 303(12), E1489-1501.

Pinheiro, P. L. C., Cardoso, J. C. R., Power, D. M., \& Canário, A. V. M. (2012). Functional characterization and evolution of PTH/PTHrP receptors: insights from the chicken. BMC Evolutionary Biology, 12, 110.

Postlethwait, J. H. (2007). The zebrafish genome in context: ohnologs gone missing. Journal of Experimental Zoology. Part B, Molecular and Developmental Evolution, 308(5), 563-577.

Rodríguez-Marí, A., Yan, Y.-L., BreMiller, R. A., Wilson, C., Cañestro, C., \& Postlethwait, J. H. (2005). Characterization and expression pattern of zebrafish anti-Müllerian hormone (amh) relative to sox9a, sox9b, and cyp19a1a, during gonad development. Gene Expression Patterns, 5(5), 655-667.

Rubin, D. A., \& Jüppner, H. (1999). Zebrafish express the common parathyroid hormone/parathyroid hormone-related peptide receptor (PTH1R) and a novel receptor (PTH3R) that is preferentially activated by mammalian and fugufish parathyroid hormonerelated peptide. The Journal of Biological Chemistry, 274(40), 28185-28190.

Sato, E., Muto, J., Zhang, L.-J., Adase, C. A., Sanford, J. A., Takahashi, T., ... Gallo, R. L. (2016). The Parathyroid Hormone Second Receptor PTH2R and its Ligand Tuberoinfundibular Peptide of 39 Residues TIP39 Regulate Intracellular Calcium and Influence Keratinocyte Differentiation. The Journal of Investigative Dermatology, 136(7), 1449-1459. 
Sato, E., Zhang, L.-J., Dorschner, R. A., Adase, C. A., Choudhury, B. P., \& Gallo, R. L. (2017). Activation of Parathyroid Hormone 2 Receptor Induces Decorin Expression and Promotes Wound Repair. The Journal of Investigative Dermatology, 137(8), 1774-1783.

Shepherd, A. J., Mickle, A. D., McIlvried, L. A., Gereau, R. W., \& Mohapatra, D. P. (2018). Parathyroid hormone-related peptide activates and modulates TRPV1 channel in human DRG neurons. European Journal of Pain (London, England), 22(9), 1685-1690.

Stednitz, S. J., McDermott, E. M., Ncube, D., Tallafuss, A., Eisen, J. S., \& Washbourne, P. (2018). Forebrain Control of Behaviorally Driven Social Orienting in Zebrafish. Current Biology, 28(15), 2445-2451.e3.

Suarez-Bregua, P., Cal, L., Cañestro, C., \& Rotllant, J. (2017). PTH Reloaded: A New

Evolutionary Perspective. Frontiers in Physiology, 8.

Swarthout, J. T., D’Alonzo, R. C., Selvamurugan, N., \& Partridge, N. C. (2002). Parathyroid hormone-dependent signaling pathways regulating genes in bone cells. Gene, 282(1-2), 117.

Tang, J., Liao, Y., He, S., Shi, J., Peng, L., Xu, X., ... Bai, L. (2017). Autocrine parathyroid hormone-like hormone promotes intrahepatic cholangiocarcinoma cell proliferation via increased ERK/JNK-ATF2-cyclinD1 signaling. Journal of Translational Medicine, 15(1), 238.

Tang, Y., Xia, H., Kang, L., Sun, Q., Su, Z., Hao, C., \& Xue, Y. (2019). Effects of Intermittent Parathyroid Hormone 1-34 Administration on Circulating Mesenchymal Stem Cells in Postmenopausal Osteoporotic Women. Medical Science Monitor: International Medical Journal of Experimental and Clinical Research, 25, 259-268. 
Thompson, M. D., Cole, D. E. C., Jose, P. A., \& Chidiac, P. (2014). G protein-coupled receptor accessory proteins and signaling: pharmacogenomic insights. Methods in Molecular Biology (Clifton, N.J.), 1175, 121-152.

Tran, T. H., Utama, F. E., Sato, T., Peck, A. R., Langenheim, J. F., Udhane, S. S., ... Rui, H. (2018). Loss of Nuclear Localized Parathyroid Hormone-Related Protein in Primary Breast Cancer Predicts Poor Clinical Outcome and Correlates with Suppressed Stat5 Signaling. Clinical Cancer Research: An Official Journal of the American Association for Cancer Research, 24(24), 6355-6366.

Tsuda, M. C., Yeung, H.-M., Kuo, J., \& Usdin, T. B. (2015). Incubation of Fear Is Regulated by TIP39 Peptide Signaling in the Medial Nucleus of the Amygdala. The Journal of Neuroscience: The Official Journal of the Society for Neuroscience, 35(35), 12152-12161.

Tsvetanova, N. G., Irannejad, R., \& von Zastrow, M. (2015). G Protein-coupled Receptor (GPCR) Signaling via Heterotrimeric G Proteins from Endosomes. The Journal of Biological Chemistry, 290(11), 6689-6696.

Vilardaga, J.-P., Bünemann, M., Feinstein, T. N., Lambert, N., Nikolaev, V. O., Engelhardt, S., ... Hoffmann, C. (2009). GPCR and G proteins: drug efficacy and activation in live cells. Molecular Endocrinology (Baltimore, Md.), 23(5), 590-599.

Vilardaga, J.-P., Jean-Alphonse, F. G., \& Gardella, T. J. (2014). Endosomal generation of cAMP in GPCR signaling. Nature Chemical Biology, 10(9), 700-706.

Violin, J. D., Crombie, A. L., Soergel, D. G., \& Lark, M. W. (2014). Biased ligands at G-proteincoupled receptors: promise and progress. Trends in Pharmacological Sciences, 35(7), 308316. 
Weaver, R. E., Mobarec, J. C., Wigglesworth, M. J., Reynolds, C. A., \& Donnelly, D. (2017). High affinity binding of the peptide agonist TIP-39 to the parathyroid hormone 2 (PTH2) receptor requires the hydroxyl group of Tyr-318 on transmembrane helix 5. Biochemical Pharmacology, 127, 71-81.

Whistler, J. L., Enquist, J., Marley, A., Fong, J., Gladher, F., Tsuruda, P., ... Von Zastrow, M. (2002). Modulation of postendocytic sorting of G protein-coupled receptors. Science (New York, N.Y.), 297(5581), 615-620.

White, A. D., Fang, F., Jean-Alphonse, F. G., Clark, L. J., An, H.-J., Liu, H., ... Vilardaga, J.-P. (2019). Ca2+ allostery in PTH-receptor signaling. Proceedings of the National Academy of Sciences of the United States of America, 116(8), 3294-3299.

Wilgus, T. A. (2017). New Mechanisms of ECM Production during Wound Healing: A Role for Parathyroid Hormone 2 Receptor Signaling. The Journal of Investigative Dermatology, 137(8), 1617-1619.

Wullimann, M. F., \& Puelles, L. (1999). Postembryonic neural proliferation in the zebrafish forebrain and its relationship to prosomeric domains. Anatomy and Embryology, 199(4), 329-348.

Xin, D., Hu, L., \& Kong, X. (2008). Alternative Promoters Influence Alternative Splicing at the Genomic Level. PLOS ONE, 3(6), e2377.

Yan, Y.-L., Bhattacharya, P., He, X. J., Ponugoti, B., Marquardt, B., Layman, J., .. Rubin, D. A. (2012). Duplicated zebrafish co-orthologs of parathyroid hormone-related peptide (PTHrP, Pthlh) play different roles in craniofacial skeletogenesis. The Journal of Endocrinology, 214(3), 421-435. 
Yang, Y., Lei, H., \& Wang, B. (2019). Effect of the PTHrP(1-34) analog abaloparatide on inducing chondrogenesis involves inhibition of intracellular reactive oxygen species production. Biochemical and Biophysical Research Communications, 509(4), 960-965.

Zhang, J., Liao, L., Li, Y., Xu, Y., Guo, W., Tian, W., \& Zou, S. (2018). Parathyroid hormonerelated peptide (1-34) promotes tooth eruption and inhibits osteogenesis of dental follicle cells during tooth development. Journal of Cellular Physiology.

Zhang, Q., Xiao, K., Paredes, J. M., Mamonova, T., Sneddon, W. B., Liu, H., ... Friedman, P. A. (2019). Parathyroid hormone initiates dynamic NHERF1 phosphorylation cycling and conformational changes that regulate NPT2A-dependent phosphate transport. The Journal of Biological Chemistry.

\section{Pez}

Allen-Petersen, B. L., Carter, C. J., Ohm, A. M., \& Reyland, M. E. (2014). Protein kinase C $\delta$ is required for ErbB2-driven mammary gland tumorigenesis and negatively correlates with prognosis in human breast cancer. Oncogene, 33(10), 1306-1315.

Belle, L., Ali, N., Lonic, A., Li, X., Paltridge, J. L., Roslan, S., ... Khew-Goodall, Y. (2015). The tyrosine phosphatase PTPN14 (Pez) inhibits metastasis by altering protein trafficking. Science Signaling, 8(364), ra18.

Brown, J. B., Boley, N., Eisman, R., May, G. E., Stoiber, M. H., Duff, M. O., ... Celniker, S. E. (2014). Diversity and dynamics of the Drosophila transcriptome. Nature, 512, 393.

Carlucci, A., Gedressi, C., Lignitto, L., Nezi, L., Villa-Moruzzi, E., Avvedimento, E. V., ... Feliciello, A. (2008). Protein-tyrosine phosphatase PTPD1 regulates focal adhesion kinase autophosphorylation and cell migration. The Journal of Biological Chemistry, 283(16), 10919-10929. 
Carlucci, A., Porpora, M., Garbi, C., Galgani, M., Santoriello, M., Mascolo, M., ... Feliciello, A. (2010). PTPD1 Supports Receptor Stability and Mitogenic Signaling in Bladder Cancer Cells. The Journal of Biological Chemistry, 285(50), 39260-39270.

Cui, T., Bell, E. H., McElroy, J., Becker, A., Gulati, P., Geurts, M., ... Chakravarti, A. (2018). miR-4516 is a Novel Prognostic Biomarker and Promotes Tumorigenesis via Targeting PTPN14-Mediated Regulation of the Hippo Pathway in Glioblastoma. International Journal of Radiation Oncology •Biology • Physics, 102(3), e176-e177.

Edwards, K., Davis, T., Marcey, D., Kurihara, J., \& Yamamoto, D. (2001). Comparative analysis of the Band 4.1/ezrin-related protein tyrosine phosphatase Pez from two Drosophila species: implications for structure and function. Gene, 275(2), 195-205.

Eikenes, A. H., Malerod, L., Lie-Jensen, A., Sem Wegner, C., Brech, A., Liestol, K., ... Haglund, K. (2015). Src64 controls a novel actin network required for proper ring canal formation in the Drosophila male germline. Development, 142(23), 4107-4118.

Ferrante, A. W., Reinke, R., \& Stanley, E. R. (1995). Shark, a Src homology 2, ankyrin repeat, tyrosine kinase, is expressed on the apical surfaces of ectodermal epithelia. Proceedings of the National Academy of Sciences of the United States of America, 92(6), 1911-1915.

Hantschel O. (2012). Structure, regulation, signaling, and targeting of abl kinases in cancer. Genes \& cancer, 3(5-6), 436-446. doi:10.1177/1947601912458584

He, C., Mao, D., Hua, G., Lv, X., Chen, X., Angeletti, P. C., ... Wang, C. (2015). The Hippo/YAP pathway interacts with EGFR signaling and HPV oncoproteins to regulate cervical cancer progression. EMBO Molecular Medicine, 7(11), 1426-1449. 
Hu, L., Xu, J., Yin, M.-X., Zhang, L., Lu, Y., Wu, W., ... Zhang, L. (2016). Ack promotes tissue growth via phosphorylation and suppression of the Hippo pathway component Expanded. Cell Discovery, 2, 15047.

Huang, J.-M., Nagatomo, I., Suzuki, E., Mizuno, T., Kumagai, T., Berezov, A., ... Wang, Q. (2013). YAP modifies cancer cell sensitivity to EGFR and survivin inhibitors and is negatively regulated by the non-receptor type protein tyrosine phosphatase 14. Oncogene, 32(17), 2220-2229.

Hunter, T. (2007). Treatment for chronic myelogenous leukemia: the long road to imatinib. Journal of Clinical Investigation, 117(8), 2036-2043.

Jodoin, J., \& C Martin, A. (2016). Abl suppresses cell extrusion and intercalation during epithelium folding. Molecular Biology of the Cell, 27.

Kwon, H. J., Waghmare, I., Verghese, S., Singh, A., Singh, A., \& Kango-Singh, M. (2015). Drosophila C-terminal Src kinase regulates growth via the Hippo signaling pathway. Developmental Biology, 397(1), 67-76.

Liu, X., Yang, N., Figel, S. A., Wilson, K. E., Morrison, C. D., Gelman, I. H., \& Zhang, J. (2013). PTPN14 interacts with and negatively regulates the oncogenic function of YAP. Oncogene, 32(10), 1266-1273.

Liu, Y.-P., Sun, X.-H., Cao, X.-L., Jiang, W.-W., Wang, X.-X., Zhang, Y.-F., \& Wang, J.-L. (2017). MicroRNA-217 suppressed epithelial-to-mesenchymal transition in gastric cancer metastasis through targeting PTPN14. European Review for Medical and Pharmacological Sciences, 21(8), 1759-1767. 
Mello, S. S., Valente, L. J., Raj, N., Seoane, J. A., Flowers, B. M., McClendon, J., ... Attardi, L. D. (2017). A p53 Super-tumor Suppressor Reveals a Tumor Suppressive p53-Ptpn14-Yap Axis in Pancreatic Cancer. Cancer Cell, 32(4), 460-473.e6.

Ogata, M., Takada, T., Mori, Y., Oh-hora, M., Uchida, Y., Kosugi, A., ... Hamaoka, T. (1999). Effects of Overexpression of PTP36, a Putative Protein Tyrosine Phosphatase, on Cell Adhesion, Cell Growth, and Cytoskeletons in HeLa Cells. Journal of Biological Chemistry, 274(18), 12905-12909.

Ogata, M., Takada, T., Mori, Y., Uchida, Y., Miki, T., Okuyama, A., ... Hamaoka, T. (1999). Regulation of Phosphorylation Level and Distribution of PTP36, a Putative Protein Tyrosine Phosphatase, by Cell-Substrate Adhesion. Journal of Biological Chemistry, 274(29), 20717-20724.

Parsons, L. M., Grzeschik, N. A., Amaratunga, K., Burke, P., Quinn, L. M., \& Richardson, H. E. (2017). A Kinome RNAi Screen in Drosophila Identifies Novel Genes Interacting with Lgl, aPKC, and Crb Cell Polarity Genes in Epithelial Tissues. G3 (Bethesda, Md.), 7(8), 24972509.

Pedraza, L. G., Stewart, R. A., Li, D.-M., \& Xu, T. (2004). Drosophila Src-family kinases function with Csk to regulate cell proliferation and apoptosis. Oncogene, 23(27), 47544762.

Perkins, L. A., Holderbaum, L., Tao, R., Hu, Y., Sopko, R., McCall, K., .. Perrimon, N. (2015). The Transgenic RNAi Project at Harvard Medical School: Resources and Validation. Genetics, 201(3), 843-852.

Pignoni, F., \& Zipursky, S. L. (1997). Induction of Drosophila eye development by decapentaplegic. Development (Cambridge, England), 124(2), 271-278. 
Poernbacher, I., Baumgartner, R., Marada, S. K., Edwards, K., \& Stocker, H. (2012). Drosophila Pez acts in Hippo signaling to restrict intestinal stem cell proliferation. Current Biology: $C B, 22(5), 389-396$.

Reddy, B. V. V. G., \& Irvine, K. D. (2013). Regulation of Hippo signaling by EGFR-MAPK signaling through Ajuba family proteins. Developmental Cell, 24(5), 459-471.

Roda-Navarro, P., \& Bastiaens, P. I. (2014). Dynamic recruitment of protein tyrosine phosphatase PTPD1 to EGF stimulation sites potentiates EGFR activation. PloS One, 9(7), e103203.

Singari, S., Javeed, N., Tardi, N. J., Marada, S., Carlson, J. C., Kirk, S., ... Edwards, K. A. (2014). Inducible protein traps with dominant phenotypes for functional analysis of the Drosophila genome. Genetics, 196(1), 91-105.

Smith, A. L., Mitchell, P. J., Shipley, J., Gusterson, B. A., Rogers, M. V., \& Crompton, M. R. (1995). Pez: a novel human cDNA encoding protein tyrosine phosphatase- and ezrin-like domains. Biochemical and Biophysical Research Communications, 209(3), 959-965.

Takahashi, M., Takahashi, F., Ui-Tei, K., Kojima, T., \& Saigo, K. (2005). Requirements of genetic interactions between Src42A, armadillo and shotgun, a gene encoding E-cadherin, for normal development in Drosophila. Development, 132(11), 2547-2559.

Tamada, M., Farrell, D. L., \& Zallen, J. A. (2012). Abl regulates planar polarized junctional dynamics through $\beta$-catenin tyrosine phosphorylation. Developmental Cell, 22(2), 309-319.

Thomas, J. H., \& Wieschaus, E. (2004). src64 and tec29 are required for microfilament contraction during Drosophila cellularization. Development, 131(4), 863-871.

Voutev, R., \& Hubbard, E. J. A. (2008). A “FLP-Out” System for Controlled Gene Expression in Caenorhabditis elegans. Genetics, 180(1), 103-119. 
Wadham, C., Gamble, J. R., Vadas, M. A., \& Khew-Goodall, Y. (2000). Translocation of protein tyrosine phosphatase Pez/PTPD2/PTP36 to the nucleus is associated with induction of cell proliferation. Journal of Cell Science, 113 ( Pt 17), 3117-3123.

Wadham, Carol, Gamble, J. R., Vadas, M. A., \& Khew-Goodall, Y. (2003). The Protein Tyrosine Phosphatase Pez Is a Major Phosphatase of Adherens Junctions and Dephosphorylates $\beta$-Catenin. Molecular Biology of the Cell, 14(6), 2520-2529.

Wang, C., Zhang, W., Yin, M.-X., Hu, L., Li, P., Xu, J., ... Zhang, L. (2015). Suppressor of Deltex mediates Pez degradation and modulates Drosophila midgut homeostasis. Nature Communications, 6, 6607.

Wilson, K. E., Li, Y.-W., Yang, N., Shen, H., Orillion, A. R., \& Zhang, J. (2014). PTPN14 forms a complex with Kibra and LATS1 proteins and negatively regulates the YAP oncogenic function. The Journal of Biological Chemistry, 289(34), 23693-23700.

Wyatt, L., Wadham, C., Crocker, L. A., Lardelli, M., \& Khew-Goodall, Y. (2007). The protein tyrosine phosphatase Pez regulates TGF $\beta$, epithelial-mesenchymal transition, and organ development. The Journal of Cell Biology, 178(7), 1223-1235.

Zandy, N. L., Playford, M., \& Pendergast, A. M. (2007). Abl tyrosine kinases regulate cell-cell adhesion through Rho GTPases. Proceedings of the National Academy of Sciences of the United States of America, 104(45), 17686-17691.

Zhang, P., Guo, A., Possemato, A., Wang, C., Beard, L., Carlin, C., ... Wang, Z. (2013). Identification and functional characterization of p130Cas as a substrate of protein tyrosine phosphatase nonreceptor 14. Oncogene, 32(16), 2087-2095. 
Zhang, S. H., Eckberg, W. R., Yang, Q., Samatar, A. A., \& Tonks, N. K. (1995). Biochemical characterization of a human band 4.1-related protein-tyrosine phosphatase, PTPH1. The Journal of Biological Chemistry, 270(34), 20067-20072.

\section{GAL4 Toxicity}

Androutsellis-Theotokis, A., Leker, R. R., Soldner, F., Hoeppner, D. J., Ravin, R., Poser, S. W., ... McKay, R. D. G. (2006). Notch signalling regulates stem cell numbers in vitro and in vivo. Nature, 442(7104), 823.

B Mahoney, M., L Parks, A., Ruddy, D., Y K Tiong, S., Esengil, H., C Phan, A., ... Curtis, D. (2006). Presenilin-Based Genetic Screens in Drosophila melanogaster Identify Novel Notch Pathway Modifiers. Genetics, 172, 2309-2324.

Bandura, J. L., \& Edgar, B. A. (2008). Yorkie and Scalloped: partners in growth activation. Developmental Cell, 14(3), 315-316.

Bollepalli, M. K., Kuipers, M. E., Liu, C.-H., Asteriti, S., \& Hardie, R. C. (2017).

Phototransduction in Drosophila Is Compromised by Gal4 Expression but not by InsP3 Receptor Knockdown or Mutation. ENeuro, 4(3).

Bertin, J., Mendrysa, S. M., LaCount, D. J., Gaur, S., Krebs, J. F., Armstrong, R. C., ... Friesen, P. D. (1996). Apoptotic suppression by baculovirus P35 involves cleavage by and inhibition of a virus-induced CED-3/ICE-like protease. Journal of Virology, 70(9), 6251-6259.

Brand, A. H., \& Perrimon, N. (1993). Targeted gene expression as a means of altering cell fates and generating dominant phenotypes. Development (Cambridge, England), 118(2), 401415. 
Campbell, S. D., Duttaroy, A., Katzen, A. L., \& Chovnick, A. (1991). Cloning and characterization of the scalloped region of Drosophila melanogaster. Genetics, 127(2), $367-380$.

Corty, M. M., Tam, J., \& Grueber, W. B. (2016). Dendritic diversification through transcription factor-mediated suppression of alternative morphologies. Development (Cambridge, England), 143(8), 1351-1362.

de Celis, JoséF., \& García-Bellido, A. (1994). Roles of the Notch gene in Drosophila wing morphogenesis. Mechanisms of Development, 46(2), 109-122.

Ellis, K., Wardwell-Ozgo, J., Moberg, K. H., \& Yedvobnick, B. (2018). The domino SWI2/SNF2 Gene Product Represses Cell Death in Drosophila melanogaster. G3: Genes, Genomes, Genetics, 8(7), 2355-2360.

Fan, Y., \& Bergmann, A. (2008). Apoptosis-induced compensatory proliferation. The Cell is dead. Long live the Cell! Trends in Cell Biology, 18(10), 467-473.

Fischer, J. A., Giniger, E., Maniatis, T., \& Ptashne, M. (1988). GAL4 activates transcription in Drosophila. Nature, 332(6167), 853-856.

Groth, A. C., Fish, M., Nusse, R., \& Calos, M. P. (2004). Construction of transgenic Drosophila by using the site-specific integrase from phage phiC31. Genetics, 166(4), 1775-1782.

Gruneberg VH. (1929). Ein Beitrag zur Kenntnis der Rontgenmutationen des X-Chromosoms von Drosophila melanogaster. Biol Zentbl 49:680-694

Guss, K. A., Nelson, C. E., Hudson, A., Kraus, M. E., \& Carroll, S. B. (2001). Control of a genetic regulatory network by a selector gene. Science (New York, N.Y.), 292(5519), 11641167. 
Guss, Kirsten A., Benson, M., Gubitosi, N., Brondell, K., Broadie, K., \& Skeath, J. B. (2013). Expression and Function of Scalloped During Drosophila Development. Developmental Dynamics : An Official Publication of the American Association of Anatomists, 242(7).

Hai, L., Zhang, C., Li, T., Zhou, X., Liu, B., Li, S., ... Yang, X. (2018). Notch1 is a prognostic factor that is distinctly activated in the classical and proneural subtype of glioblastoma and

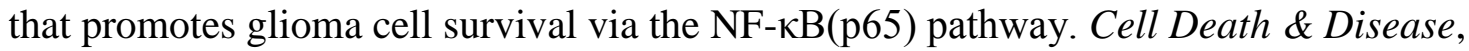
9(2).

Halder, G., Polaczyk, P., Kraus, M. E., Hudson, A., Kim, J., Laughon, A., \& Carroll, S. (1998). The Vestigial and Scalloped proteins act together to directly regulate wing-specific gene expression in Drosophila. Genes \& Development, 12(24), 3900-3909.

Hay, B. A., Wolff, T., \& Rubin, G. M. (1994). Expression of baculovirus P35 prevents cell death in Drosophila. Development (Cambridge, England), 120(8), 2121-2129.

Jafar-Nejad, H., Tien, A.-C., Acar, M., \& Bellen, H. J. (2006). Senseless and Daughterless confer neuronal identity to epithelial cells in the Drosophila wing margin. Development, 133(9), $1683-1692$.

Jenett, A., Rubin, G. M., Ngo, T.-T. B., Shepherd, D., Murphy, C., Dionne, H., ... Zugates, C. T. (2012). A GAL4-Driver Line Resource for Drosophila Neurobiology. Cell Reports, 2(4), $991-1001$.

Jory, A., Estella, C., Giorgianni, M. W., Slattery, M., Laverty, T. R., Rubin, G. M., \& Mann, R. S. (2012). A survey of 6300 genomic fragments for cis-regulatory activity in the imaginal discs of Drosophila melanogaster. Cell Reports, 2(4), 1014-1024.

Koto, A., Kuranaga, E., \& Miura, M. (2011). Apoptosis Ensures Spacing Pattern Formation of Drosophila Sensory Organs. Current Biology, 21(4), 278-287. 
Kramer, J. M., \& Staveley, B. E. (2003). GAL4 causes developmental defects and apoptosis when expressed in the developing eye of Drosophila melanogaster. Genetics and Molecular Research, 6.

Krupp, J. J., Yaich, L. E., Wessells, R. J., \& Bodmer, R. (2005). Identification of Genetic Loci That Interact With cut During Drosophila Wing-Margin Development. Genetics, 170(4), $1775-1795$.

Lin, C.-C., \& Potter, C. J. (2016). Editing Transgenic DNA Components by Inducible Gene Replacement in Drosophila melanogaster. Genetics, 203(4), 1613-1628.

Liu, Y., \& Lehmann, M. (2008). A genomic response to the yeast transcription factor GAL4 in Drosophila. Fly, 2(2), 92-98.

Pfeiffer, B. D., Jenett, A., Hammonds, A. S., Ngo, T.-T. B., Misra, S., Murphy, C., ... Rubin, G. M. (2008). Tools for neuroanatomy and neurogenetics in Drosophila. Proceedings of the National Academy of Sciences of the United States of America, 105(28), 9715-9720.

Vaccari, T., \& Bilder, D. (2005). The Drosophila tumor suppressor vps25 prevents nonautonomous overproliferation by regulating notch trafficking. Developmental Cell, 9(5), 687-698.

Williams, J. A., Bell, J. B., \& Carroll, S. B. (1991). Control of Drosophila wing and haltere development by the nuclear vestigial gene product. Genes \& Development, 5(12B), 24812495. 


\section{APPENDIX A: METHODS AND MATERIALS}

\section{Isolation of total RNA from Zebrafish}

Illinois State University Biosafety and IACUC protocols (04B-2011 and 15-2011) were adhered to at all times. Purchase of adult zebrafish was done through a commercial supplier. Zebrafish were euthanized by Tricaine solution (400 mg/100 ml, Sodium Bicarbonate buffered water, Western Chemical Inc.) and placed in liquid nitrogen just prior to being homogenized in 9mL guanidinium thiocyanate (TRIzol, Life Technologies). 5' RACE (Roche Life Sciences) was performed according to kit instructions. Initial reverse 5'RACE primer was designed complementary to sequence within exon 2 of the predicted in silico pth2rb sequence (RACE_E2_RT). 5' RACE pth2rb transcripts were ligated into pCDNAI/Amp and pGEMT-easy plasmids for subcloning and sequencing. Sequencing of $p t h 2 r b$ cDNA was performed at Univ. of Illinois Urbana-Champaign Core Sequencing Facility. Full length $p t h 2 r b$ was amplified by PCR from 1st strand RT-PCR synthesized cDNA (from primer Pth2rb_3UTR_RT) with primers at the 5' UTR of the 5' RACE sequence (Pth2rb_5UTR_3) and complementary to the pth2rb 3'UTR (Pth2rb_3UTR_2). Full-length $p t h 2 r b$ was ligated into pCDNAI/Amp and pGEMT-easy.

Primers:

Pth2rb_3UTR_RT: TCCAGTTTCAATCATGAACGTATCC

RACE_E2_RT: CGCAGCATGAACGACACAAATAG

Pth2rb_5UTR_3: AGCTGGATAAACCCACCGGA

Pth2rb_3UTR_2: GTCAGGTTTTTTTAAAGTACTTCCTC

\section{Sequence analysis.}

All six PTH receptor homologs from human and Danio rerio were identified by BLAST. Multi-alignment was made using PSI/TM-Coffee (http://tcoffee.crg.cat; Floden et al. 2016), then manually edited to reduce weakly-supported gaps. Sequence files aligned: NP_000307;

NP_571432; NP_571453; NP_005039; NP_571452; XP_017208978. Figure made by inputting 
alignment to Multiple Align Show at The Sequence Manipulation Suite (bioinformatics.org), using this set of similarity groups: (FILMVW) (KR) (DE) (ST). Output was annotated manually in Photoshop. The structure figures (4-5) were made from PDB 6FJ3 using CCP4 Molecular Graphics Program v2.10.10 (www.ccp4.ac.uk; Winn et al. 2011).

\section{In situ hybridization}

Embryos of various stages were cryosectioned and sections were used for in situ hybridization as described (Rodríguez-Marí et al. 2005). Probe synthesis and whole mount in situ hybridization analyses were performed as previously described by (Jowett \& Yan, 1996).

Complementary RNA (cRNA) probes were produced by using the following restriction enzymes and RNA polymerases: antisense $p t h 2 r a$, BamHI and SP6; antisense $p t h 2$, SphI and SP6. Pth2rb in pCDNAI/AMP was linearized with BamHI prior to cRNA synthesis with SP6 polymerase.

\section{Cell transfection and PTHR plasmids}

An HEK-293 cell line (GS-22A) that stably expresses the luciferase-based pGloSensor22F (GloSensor) cAMP reporter plasmid (Promega Corp. USA) was used for cAMP liganddose-response analyses. The cells were seeded in white 96-well plates and, when $80 \%$ confluent, were transfected using Fugene-6 reagent with plasmid DNA encoding either the human PTH1R (hPTH1R), human PTH2R (hPTH2R), zebrafish Pth2ra (zPth2ra) or zebrafish Pthr2b (zPth2rb) and 80 ng DNA per well. The plasmid vector used for expressing hPTH1R and hPTH2R was pCDNA3.1(+).

\section{GloSensor assays of cAMP signaling}

Two days after transfection when the GS-22A cells were confluent, the media was replaced with $\mathrm{CO}_{2}$-independent medium containing BSA $(0.1 \%$, Sigma $)$ and luciferin $(0.5 \mathrm{mM}$, Biotium); and incubated for 20 minutes at room temperature. Then test ligands at varying 
concentrations were added and incubations continued for an additional period of up to 90 minutes, during which time changes in luminescence arising from intracellular cAMP binding to the GloSensor reporter protein were measured at two-minute intervals using a PerkinElmer Envision plate reader. Ligand dose-response curves were generated using the peak luminescence response measured for each well/ligand concentration, which typically occurred $\sim 20$ minutes after ligand addition.

\section{cAMP data calculations}

Data were processed using Excel 2008 (Microsoft Corp. Redmond, WA) and Prism 5.0 (GraphPad Software Inc., La Jolla, CA). Aggregate data are expressed as means \pm S.E.M. Curves were fit to the data using a four-parameter, non-linear regression function. Statistical analyses were performed using the Student's t-test (two-tailed, unequal variances), significance was inferred from $\mathrm{P}$ values of less than 0.05 .

\section{Pez crosses and confocal analysis}

Pez overexpression marker line 'UAS-Pez':

[Hsp70-FLP], [Act5C>CD2>GAL4]; [GMR-GAL4], [UAS-Pez]; [UAS-mCD8-mCherry]

UAS-Pez marker line (males) was crossed with virgin females from RNAi stocks. These flies carry an $A c t 5 C>C D 2>G A L 4$ construct; heat shock induction of FLP recombinase triggers excision of the $C D 2$ stuffer fragment, allowing high-level GAL4 production from the $A c t 5 C$ promoter in random clones of cells. Before ovary dissection, 5-8 females were transferred to a new tube with fresh yeast and males to stimulate egg production. Flies were heat shocked for 50 mins at $38 \mathrm{C}$ and then transferred to a $25 \mathrm{C}$ chamber for 2.5 days. Ovaries were dissected in 1x PBS and immediately fixed for 15 min in $2 \%$ Formaldehyde. Ovaries were washed in 1x PBS 3-4 times and then transferred to 1x PBT (PBS + Triton 0.2\%). Tissues were 
blocked with PBT $+4 \%$ goat serum for 45 mins at room temperature. Primary antibodies

(1:1000 dil) were added to ovaries overnight at $4 \mathrm{C}$ or $5 \mathrm{hr}$ at room temperature in $\mathrm{PBT}+1 \%$ goat serum (PBTG) (Singari et al. 2014; Pignoni and Zipursky 1997). Ovaries were washed 3-4 times with PBTG before incubation with secondary antibodies overnight at 4C. Ovaries were washed with PBTG and mounted on slides in vectashield.

\section{$s d^{R 94 B 03}-G A L 4$ wing disc dissection}

Wing discs were dissected from $3^{\text {rd }}$ instar larvae in 1x PBS and immediately fixed for 15 min in $2 \%$ Formaldehyde. Wing discs were then mounted in vectashield prior to imaging by fluorescent microscopy to detect GFP.

\section{Contributing work in:}

Dale, M. D., Mortimer, E. M., Kolli, S., Achramowicz, E., Borchert, G., Juliano, S. A., ... Rubin, D. A. (2015). Bone-Remodeling Transcript Levels Are Independent of Perching in End-of-Lay White Leghorn Chickens. International Journal of Molecular Sciences, 16(2), 2663-2677.

\section{Cloning cDNA for Sequence Validation:}

All amplicons generated by qPCR were electrophoresed, excised, ligated into pGEMTeasy (Promega), transformed into TOP 10 E. coli cells (Invitrogen, Carslbad, CA, USA), screened and sequenced with T7 and Sp6 primers, as previously described (Yan et al. 2012). The subcloning and DNA sequencing was performed to validate the amplicons generated. Using this information, final validated primer pairs were subsequently selected for each locus. 
APPENDIX B: SUPPLEMENTARY TABLES \& FIGURES

\begin{tabular}{llll} 
Abbreviation & Full gene name & CG number & FlyBase record \# \\
\hline Abl & Abl tyronsine kinase & CG4032 & FBgn0000017 \\
Ack & Activated Cdc42 kinase & CG14992 & FBgn0028484 \\
Ack-like & Activated Cdc42 kinase-like & CG43741 & FBgn0263998 \\
Alk & Anaplastic lymphoma kinase & CG8250 & FBgn0040505 \\
Btk29A & Btk family kinase at 29A & CG8049 & FBgn0003502 \\
Btl & Breathless & CG32134 & FBgn0285896 \\
Cad96Ca & Cadherin 96Ca & CG10244 & FBgn0022800 \\
CG3277 & CG3277 & CG3277 & FBgn0031518 \\
Csk & C-terminal Src kinase & CG42317 & FBgn0262081 \\
Ddr & Discoidin domain receptor & CG33531 & FBgn0053531 \\
dnt & Doughnut on 2 & CG17559 & FBgn0024245 \\
drl & derailed & CG17348 & FBgn0015380 \\
Drl-2 & Derailed 2 & CG3915 & FBgn0033791 \\
Egfr & Epidermal growth factor receptor & CG10079 & FBgn0003731 \\
Eph & Eph receptor tyrosine kinase & CG1511 & FBgn0025936 \\
Fak & Focal adhesion kinase & CG10023 & FBgn0020440 \\
Fer & FER tyrosine kinase & CG8874 & FBgn0000723 \\
Hop & hopscotch & CG1594 & FBgn0004864 \\
htl & heartless & CG7223 & FBgn0010389 \\
InR & Insulin-like receptor & CG18402 & FBgn0283499 \\
Nrk & Neurospecific receptor kinase & CG4007 & FBgn0020391 \\
otk & Off-track & CG8967 & FBgn0004839 \\
Pvr & PDGF- and VEGF-receptor related & CG8222 & FBgn0032006 \\
Ret & Ret oncogene & CG14396 & FBgn0011829 \\
Ror & Ror & CG4926 & FBgn0010407 \\
sev & sevenless & CG18085 & FBgn0003366 \\
Shark & SH2 ankyrin repeat kinase & CG18247 & FBgn0015295 \\
Src42A & Src oncogene at 42A & CG44128 & FBgn0264959 \\
Src64B & Src oncogene at 64B & CG7524 & FBgn0262733 \\
Tie & Tie-like receptor tyrosine kinase & CG7525 & FBgn0014073 \\
tor & torso & CG1389 & FBgn0003733 \\
Wee1 & Wee1 kinase & CG4488 & FBgn0011737 \\
Wsck & Wsck & CG31127 & FBgn0046685
\end{tabular}

Supplemental Table 1. Comprehensive list of candidate cytoplasmic tyrosine kinases for RNAi knockdown in UAS-Pez. (*) indicates CTK knockdowns described in this this work. 


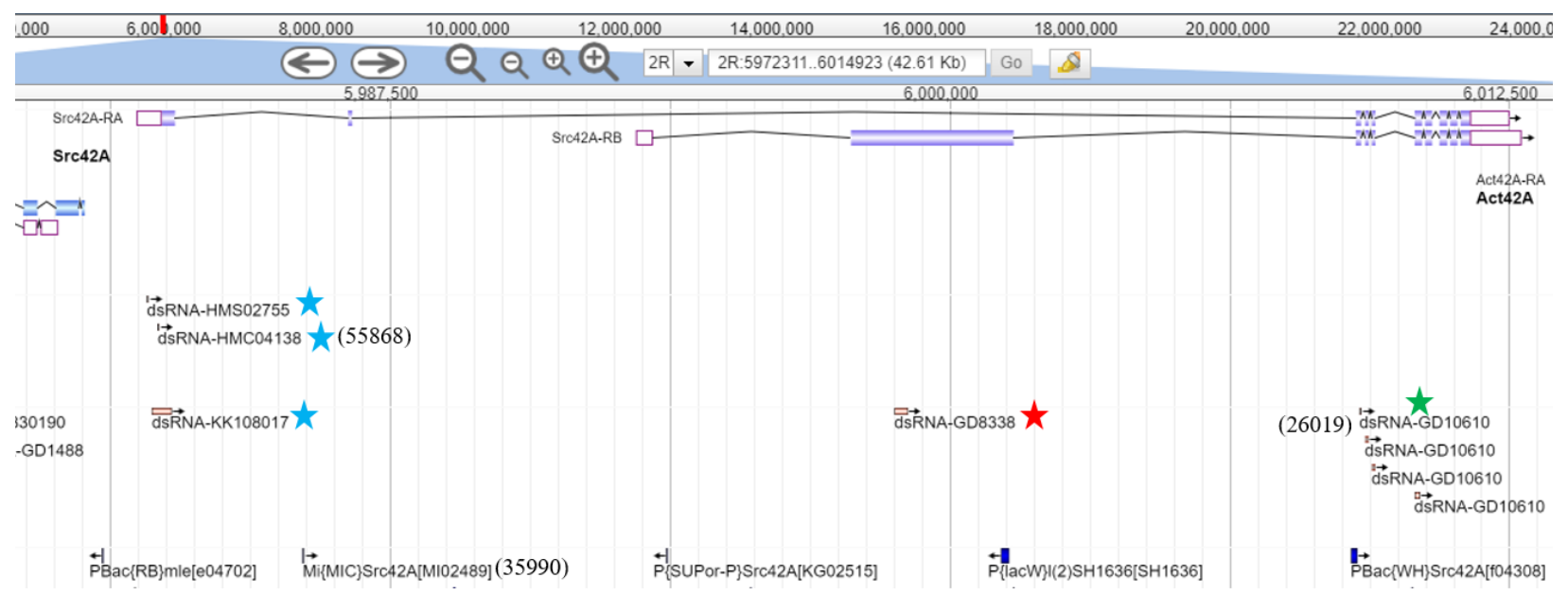

Supplemental Figure 1. Map of Src42A targeting RNAi lines crossed to UAS-Pez. Src42A

TRiP RNAi knockdown lines targeting Src42A-A (Blue stars), Src42A-B (Red Star), or both forms via their conserved C-terminus of $\operatorname{Src} 42 A-A /-B$ (Green star).

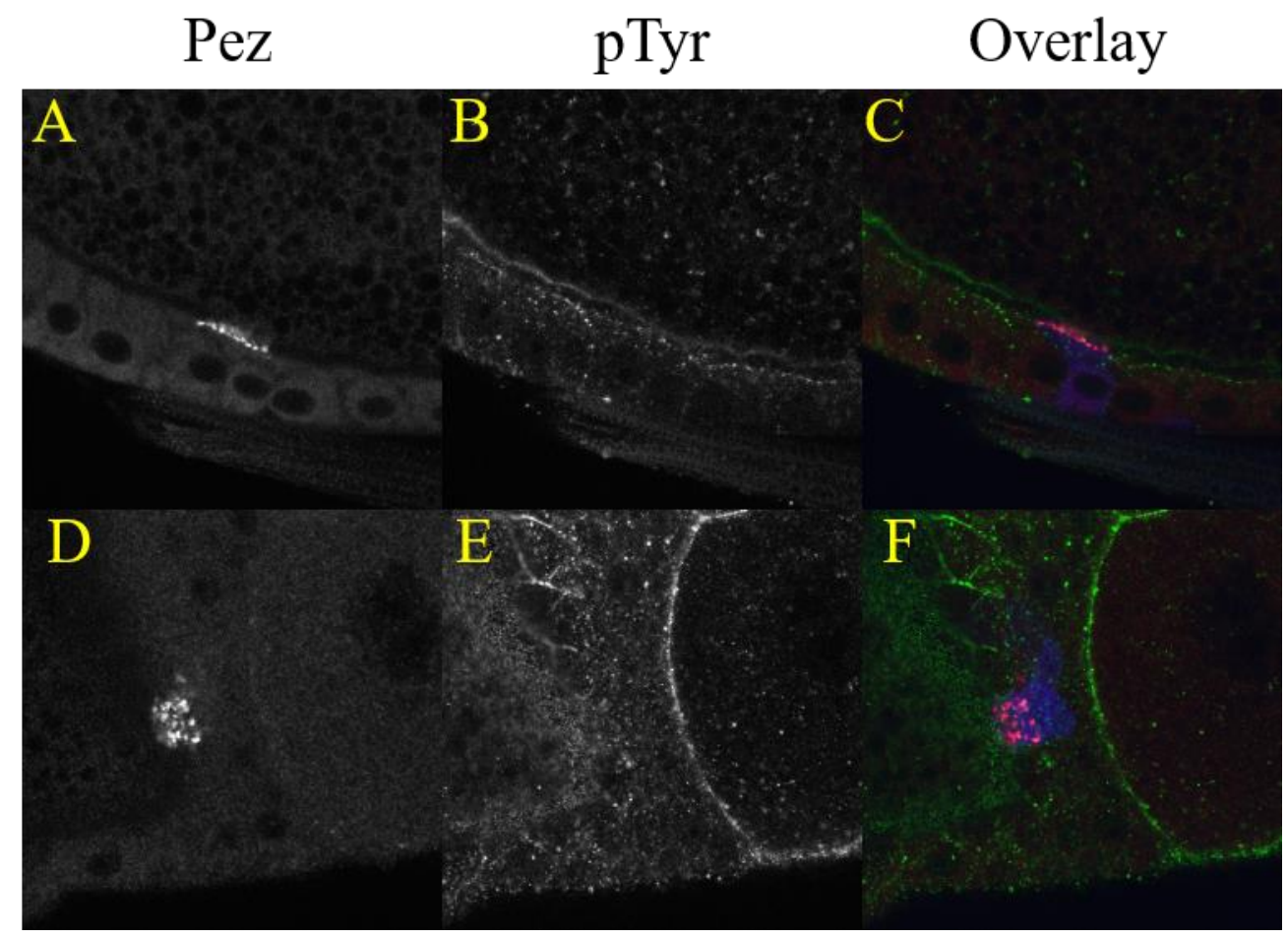

Supplemental Figure 2. UAS-Pez crossed to Src42A RNAi (55868). Additional confocal images of clonal follicle cells overexpressing Pez and Src42A RNAi (55868) knockdown. Pez visible in overlay as red, pTyr in green, and mCD8-RFP clone marker in blue. 